University of Nebraska - Lincoln

DigitalCommons@University of Nebraska - Lincoln

Publications, Agencies and Staff of the U.S.

Department of Commerce

U.S. Department of Commerce

2012

\title{
Estimation of surface albedo and directional reflectance from Moderate Resolution Imaging Spectroradiometer (MODIS) observations
}

\author{
Tao He \\ University of Maryland, the@umd.edu \\ Shunlin Liang \\ University of Maryland \\ Dongdong Wang \\ University of Maryland \\ Hongyi Wu \\ Institute of Mountain Hazards and Environment \\ Yunyue Yu \\ NOAA/NESDIS/STAR
}

See next page for additional authors

Follow this and additional works at: https://digitalcommons.unl.edu/usdeptcommercepub

Part of the Environmental Sciences Commons

He, Tao; Liang, Shunlin; Wang, Dongdong; Wu, Hongyi; Yu, Yunyue; and Wang, Jindi, "Estimation of surface albedo and directional reflectance from Moderate Resolution Imaging Spectroradiometer (MODIS) observations" (2012). Publications, Agencies and Staff of the U.S. Department of Commerce. 341. https://digitalcommons.unl.edu/usdeptcommercepub/341

This Article is brought to you for free and open access by the U.S. Department of Commerce at DigitalCommons@University of Nebraska - Lincoln. It has been accepted for inclusion in Publications, Agencies and Staff of the U.S. Department of Commerce by an authorized administrator of DigitalCommons@University of Nebraska - Lincoln. 


\section{Authors}

Tao He, Shunlin Liang, Dongdong Wang, Hongyi Wu, Yunyue Yu, and Jindi Wang 


\title{
Estimation of surface albedo and directional reflectance from Moderate Resolution Imaging Spectroradiometer (MODIS) observations
}

\author{
Tao He ${ }^{\mathrm{a}, *}$, Shunlin Liang ${ }^{\mathrm{a}}$, Dongdong Wang ${ }^{\mathrm{a}}$, Hongyi $\mathrm{Wu}^{\mathrm{b}}$, Yunyue $\mathrm{Yu}^{\mathrm{c}}$, Jindi Wang ${ }^{\mathrm{d}}$ \\ a Department of Geography, University of Maryland, College Park, MD 20742, USA \\ b Institute of Mountain Hazards and Environment, CAS, Chengdu 610041, China \\ c NOAA/NESDIS/STAR, Camp Springs, MD 20746, USA \\ d State Key Laboratory of Remote Sensing Science, School of Geography, Beijing Normal University, Beijing 100875, China
}

\section{A R T I C L E I N F O}

\section{Article history:}

Received 20 May 2011

Received in revised form 4 January 2012

Accepted 8 January 2012

Available online 31 January 2012

\section{Keywords}

MODIS

Albedo

Directional reflectance

Radiative transfer

Aerosol optical depth

\begin{abstract}
A B S T R A C T
Land surface albedo is one of the key geophysical variables controlling the surface radiation budget. In recent years, land surface albedo products have been generated using data from various satellites. However, some problems exist in those products due to either the failure of the current retrieving procedures resulting from persistent clouds and/or abrupt surface changes, or the reduced temporal or spatial coverage, which may limit their applications. Rapidly generated albedo products that help reduce the impacts of cloud contamination and improve the capture of events such as ephemeral snow and vegetation growth are in demand.

In this study, we propose a method for estimating the land surface albedo from Moderate Resolution Imaging Spectroradiometer (MODIS) data using a short temporal window. Instead of executing the atmospheric correction first and then fitting the surface reflectance in the current MODIS albedo procedure, the atmospheric properties (e.g., aerosol optical depth) and surface properties (e.g., surface bidirectional reflectance) were estimated simultaneously. Validations were carried out using various data sources including ground measurements (e.g., from the Surface Radiation (SURFRAD) Network and Greenland Climate Network (GC-Net)) and MODIS AERONET-based Surface Reflectance Validation Network (MODASRVN) data. The results showed comparable albedo estimates with both MODIS data and ground measurements, and the MODASRVN instantaneous surface reflectance was in good agreement with the reflectance estimation from our method. Aerosol optical depth (AOD) retrievals over SURFRAD and MODASRVN sites were also compared with ground measurements. Validation results showed estimation accuracies similar to those of MODIS aerosol products.
\end{abstract}

(c) 2012 Elsevier Inc. All rights reserved.

\section{Introduction}

Land surface albedo is a key geophysical parameter controlling the energy budget in land-atmosphere interactions (Dickinson, 1983). Land surface albedo varies spatially and evolves seasonally based on solar illumination changes, vegetation growth, and human activities such as cutting/planting forests and slash-and-burn agricultural practices. A sensitivity analysis, which was done by estimating the impacts of albedo uncertainties in climate modeling, shows that an absolute albedo accuracy between \pm 0.02 and \pm 0.03 , equivalent to $\pm 10 \mathrm{~W} \mathrm{~m}^{-2}$, results in significant changes in regional climate simulations (Nobre et al., 1991; Sellers et al., 1995).

Satellite remote sensing is an essential technique for estimating land surface albedo at various spectral, spatial, temporal, and angular resolutions. During the last decade, many satellite-generated albedo products have been derived. However, in terms of albedo changes

\footnotetext{
* Corresponding author. Tel.: + 13014054538.

E-mail address: the@umd.edu (T. He).
}

over the globe across a relatively long time period (several years to decades), different trends have been found based on the analyses of different global albedo products. A recent study on the 10-year (2000-2009) MODIS albedo product showed significant differences among albedo products generated by different satellite data (e.g., MODIS, ISCCP and GEWEX) (Zhang et al., 2010).

Many researchers have developed algorithms for various sensors to derive albedo directly from satellite observations. The AVHRR algorithm provides global coverage of albedo products (Strugnell \& Lucht, 2001). POLDER and MISR allow researchers to use multi-angular information to obtain a better understanding of surface reflectance anisotropy (Diner et al., 1999; Leroy et al., 1997). The MODIS albedo product (Schaaf et al., 2002) utilizes multiple spectral bands to derive accurate broadband albedo estimations at both high spatial and high temporal resolutions. With the development of geostationary satellite sensors, many research interests have focused on deriving the diurnal changes of surface albedo based on a much wider range of solar illumination angles, such as the Meteosat/SEVIRI albedo product (Geiger et al., 2008; Pinty et al., 2000). 
Retrieval of data pertaining to aerosol distribution and properties over land with the help of the "dark object" atmospheric correction algorithm in products from satellite sensors such as MODIS and SEVIRI have yielded valuable results. However, the use of this algorithm is restricted to land surface with low reflectance (e.g., water and dense vegetation), while over bright surfaces (snow covered areas, etc.) it often fails to estimate the aerosol information accurately. In other words, this algorithm, which is based on densely vegetated areas, cannot rely on atmospheric correction to retrieve the surface reflectance and albedo over highly reflective surfaces. Alternative solutions have been proposed to estimate the albedo from bright surfaces using direct estimation methods (Liang, 2003; Liang et al., 1999, 2005). These methods have shown good results in deriving broadband shortwave albedo. However, the direct estimation methods cannot estimate spectral albedo or surface reflectance.

The other problem of separating the atmospheric correction and the surface bidirectional reflectance factor (BRF) fitting lies in the Lambertian approximation in the radiative transfer procedure. Both the atmospheric path and surface directional reflectance will change with solar and viewing angles (as the scattering path changes). However, a Lambertian surface is often assumed in atmospheric corrections when the surface BRF is not known. As a result, biases emerge with "atmospheric corrected surface reflectance" and further deteriorate the BRF fitting results. Furthermore, the long-time composite albedo products cannot satisfy the needs of the weather forecast or the land surface modeling when rapid changes occur such as snow fall/melt, forest fire/clear-cut and crop harvesting. The diurnal albedo signature cannot be estimated in the current algorithms because of the Lambertian approximation in some of the atmospheric correction algorithms. Prior knowledge has not been effectively utilized in the current algorithms. Moreover, the current observation accumulation method makes it difficult to obtain sufficient observations when persistent clouds exist within the accumulation window.

In recent studies, surface reflectance and AOD were retrieved jointly using the optimization method based on the SEVIRI data (Govaerts et al., 2010; Wagner et al., 2010). In the algorithm, however, the aerosol's information is retrieved as the average of its daily distribution. Also, the climatology information is not fully utilized to constrain the estimation. Given the fine temporal resolution of geostationary satellite observations, the full use of the broad range of solar angular distribution during a day can be made by adding the aerosol variables to its retrieving procedure. Additionally, multiple spectral bands in the shortwave range provide better capability in terms of capturing the aerosol information and surface spectral information in the estimation of the broadband energy budget. Based on a similar principle, this paper proposes an improved algorithm using multi-date MODIS data to account for both the surface anisotropy and the temporal variations of the AOD to improve the estimation of surface albedo and bidirectional reflectance. The theoretical concepts and a brief introduction of the retrieving algorithm are presented in Section 2. Section 3 describes the implementation of our algorithm on the pixel basis and the preparations of the input data sets. Some validation results are presented in Section 4 and finally, a brief conclusion is presented in Section 5 .

\section{Methodology}

\subsection{Overall framework}

Currently, to obtain the broadband shortwave albedo estimations most albedo retrieving algorithms require three major procedures: atmospheric correction, surface BRF fitting, and narrowband-to-broadband conversion. With each procedure implemented separately, errors propagate from the atmospheric correction to the final broadband albedo estimates irrespective of the algorithms used. To avoid these increasing errors, it is advantageous to combine those procedures. In the framework of this proposed MODIS surface albedo estimation algorithm, several components are included: atmospheric radiative transfer process with anisotropic reflectance of land surface, surface albedo/BRF modeling, and albedo climatology.

Based on the available prior information on albedo and the satellite observations, the unknown variables (e.g., the surface BRF kernel parameters, AOD) are determined in the context of the least-square approach through the minimization of the cost function:

$J(X)=\left(A(X)-A^{C l m}\right) B^{-1}\left(A(X)-A^{C l m}\right)+\left(R^{E s t}(X)-R^{O b s}\right) O^{-1}\left(R^{E s t}(X)-R^{O b s}\right)+J_{c}$

Here, $X$ denotes the unknown variables to be estimated in one sliding window and it includes the surface BRF model parameters and AOD. Two general assumptions are made here to reduce the complexity of the retrieving procedure and to generate the stable estimates as well: 1) the surface BRF shape is stable within the sliding window; 2) the aerosol type and its properties (e.g. Angström exponent) do not change within the sliding window, but AOD varies from time to time. Since the predefined aerosol types are used in this study, the intrinsic properties for each of the aerosol types are not part of the unknown variables to be estimated. Then, $X$ can be written in the following form:

$X=\left[B R F_{1}, B R F_{2}, \ldots, B R F_{N B}, A O D_{1}, A O D_{2}, \ldots, A O D_{N O}\right]^{T}$,

$N B$ is the number of spectral bands from a certain satellite sensor, $N O$ is the number of cloud-free observations involved in the inversion, $B R F_{i} i \in[1, N B]$ is a set of BRF model parameters (e.g. for kernel models, one set of $B R F_{i}$ refers to three parameters: $f_{i s o}, f_{v o l}$, and $f_{\text {geo }}$ ), $A O D_{j} j \in[1, N O]$ is the AOD value for the corresponding observation $j$, and $R_{i, j}^{O b s}$ and $R_{i, j}^{E s t}$ refer to the observed and modeled TOA reflectance for a band and a given set of geometries (e.g., solar angle and viewing angle), respectively.

$R_{i, j}^{O b s}$ are obtained from satellite observations. However, $R_{i, j}^{E s t}$ values need to be derived by a forward simulation based on the radiative transfer procedures from both surface and atmosphere components. For this purpose, the use of the atmospheric radiative transfer formulation with surface BRF is recommended. In this manner, $R_{i, j}^{E s t}$ can be expressed using both the surface properties (e.g., albedo and BRF) and the atmospheric properties (e.g., AOD, water vapor, and ozone).

$A(X)$ is the calculated broadband surface albedo, and $A^{\mathrm{Clm}}$ is the prior information of broadband albedo from albedo climatology. Albedo climatology is used to constrain the retrieving procedure of surface albedo and reflectance. It describes the major seasonal and interannual changes in the surface signature. At this stage, multiyear satellite albedo products are collected to form the spatially and temporally continuous and complete albedo climatology. $B$ and $O$ are the error matrices for the climatology and the fitting of satellite remotely sensed data, respectively. As the uncertainties for both the climatology and the data fitting involve a large number of components, most of which are difficult to estimate, two simplifications need to be made here: 1 ) the albedo climatology used here is unbiased, and $B$ is calculated from the uncertainty of the albedo climatology using multiyear satellite albedo products; 2 ) reflectances are band-independent and the diagonal components of $O$ are determined by the magnitude of spectral reflectance multiplied by the contribution to the shortwave albedo for each band. $J_{c}$ is the penalty function accounting for the validity of BRF values calculated from the estimated BRF parameters, etc. For any particular geometry, when the reflectance or albedo calculated from the BRF model is negative or greater than one, $J_{c}$ is set to a large value (e.g., 100). In addition, all the BRF model parameters are constrained to be non-negative, in particular for the kernel model used in this study. To minimize the cost function $J(X)$, the optimal values of $X$ having physical meaning need to be found. However, 
owing to the non-linearity of the atmospheric radiative transfer equations and the dimensions of the unknown variables, it is always difficult to find the optimal values that can minimize the cost function globally. The algorithm of the shuffled complex evolution (SCE) (Duan et al., 1993, 1994) is used here to obtain physically reasonable global optimal estimations based on albedo climatology and surface BRF model priors. The overall framework is shown in Fig. 1.

\subsection{Atmosphere radiative transfer formulation with surface BRF models}

The satellite-observed radiance contains information from both the atmospheric components (aerosol, water vapor, ozone, etc.) and the land surface reflectivity. Aerosol properties, such as optical depth, size distribution, and refractive index have a great impact on the representation of land surface information in the satellite observations. Instead of using a "dark object" algorithm, it is advantageous to combine the retrieval of both the AOD and the surface BRF parameters from the TOA reflectance in the radiative transfer process. In order to do so, the relationship between TOA reflectance, AOD, and surface BRF needs to be established.

Theoretically, the overall procedure proposed here is similar to the proposed algorithm based on the MSG/SEVIRI data (Govaerts et al., 2010; Wagner et al., 2010), which retrieves the daily aerosol and surface reflectance simultaneously. Since the overall retrieving procedure is underdetermined, which means there are fewer observations than unknown variables, an assumption needs to be made, as follows: as the surface properties change slowly, the surface BRF shape is assumed to be invariant within a sliding window ( 7 days or less). A smaller window size results in better capability over a rapidly changing surface. Cloudfree observations are collected within the sliding window. However, the number of collected observations should be limited in order to reflect the rapid change in the surface. Only those observations that are closest to the center of the sliding window are used in one procedure to retrieve surface BRF and AOD simultaneously. Details on how the minimum number of cloud-free MODIS observations can be determined are discussed in Section 3.1. Given the surface BRF and AOD retrievals, the instantaneous "blue-sky" albedo can be calculated based on the black-sky and white-sky albedo using diffuse skylight ratio:

$\alpha_{\text {blue }}=f_{\text {dif }} \cdot \alpha_{\text {ws }}+\left(1-f_{\text {dif }}\right) \cdot \alpha_{b s}$

Here, $\alpha_{\text {blue }}, \alpha_{b s}$, and $\alpha_{w s}$ are the blue-sky, black-sky, and white-sky albedo, respectively, and $f_{\text {dif }}$ is the diffuse skylight ratio.

Based on the comparison with the SEVIRI estimating procedure, the proposed algorithm for MODIS has several improvements in terms of coupling the land-atmosphere radiation interaction, as follows:

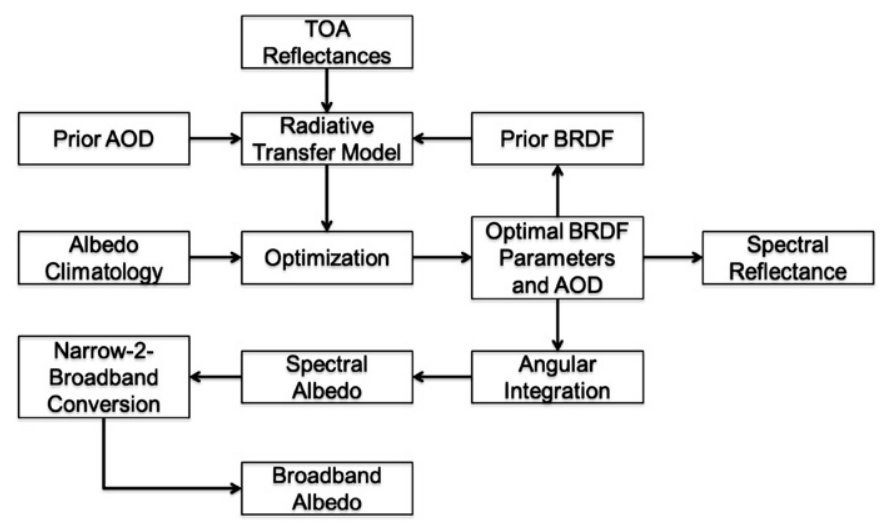

Fig. 1. Flowchart of estimating surface albedo and reflectance.
1) The AOD is treated as non-identical throughout the retrieving temporal window. Since satellite observations within the sliding window can sometimes have a broad range of solar/viewing zenith/azimuth angles, assuming only that the aerosol does not change within the retrieving temporal window does not fully utilize the abundant angular information that can capture the directional variation in the surface reflectivity. Moreover, this assumption is not valid over such a long time period (one day or more, etc.) and can bias the atmospheric correction at large angles.

2) Many forward models have been proposed recently to approximate different components of radiation fluxes at the media boundary. These models include various two-stream methods (Meador \& Weaver, 1980) and four-stream methods (Liang \& Strahler, 1994, 1995). However, although two-stream models are time-efficient, their accuracy is low. Instead of using the radiative transfer model with a two-stream approximation, this study adopted a simple and fast 3D formulation of radiative transfer by incorporating the surface BRF models (Qin et al., 2001). The authors state that this approach does not introduce any approximation into the formulation, and their numerical experiments demonstrate that this formulation is very accurate (Qin et al., 2001). The TOA reflectance $\rho_{a}$ is expressed as

$$
\begin{aligned}
\rho_{a}\left(\Omega_{s}, \Omega_{v}\right)= & \rho_{0}\left(\Omega_{s}, \Omega_{v}\right) \\
& +\frac{T\left(\Omega_{s}\right) R\left(\Omega_{s}, \Omega_{v}\right) T\left(\Omega_{v}\right)-t_{d d}\left(\Omega_{s}\right) t_{d d}\left(\Omega_{v}\right)\left|R\left(\Omega_{s}, \Omega_{v}\right)\right| \rho}{1-r_{h h} \rho}(4)
\end{aligned}
$$

In the equation, $\Omega_{S} \in\left(\theta_{s}, \phi_{s}\right)$ is the solar incoming direction and $\Omega_{v} \in\left(\theta_{v}, \phi_{v}\right)$ is the viewing direction. There are two groups of coefficients in the above equation that are independent of each other: atmosphere-dependent and surface-dependent coefficients. The coefficients in each group represent the inherent properties of either the atmosphere or the surface and can be regarded as separate groups.

For the atmosphere, $\rho_{0}\left(\Omega_{s}, \Omega_{v}\right)$ is the atmospheric reflectance associated with path radiance, $\rho$ is the atmospheric spherical albedo, and $T\left(\Omega_{S}\right)$ and $T\left(\Omega_{v}\right)$ are defined as combinations of direct transmittance $\left(t_{d d}\right)$ and directional-hemispheric (or hemispheric-directional) transmittance $\left(t_{d h}\right.$ and $\left.t_{h d}\right)$, respectively. For the algorithm implementation, it is usually very time-consuming to calculate each element in the transmittance matrices together with the atmospheric reflectance. To expedite the computation for the forward modeling, those atmospheric variables are pre-calculated by simulation using the radiative transfer software 6S (Kotchenova et al., 2006) and stored in the look-up table (LUT). Details on the design of the LUT are given in Section 3.2.

For the surface, the reflectance matrix is defined as

$R\left(\Omega_{s}, \Omega_{v}\right)=\left[\begin{array}{cc}r_{d d}\left(\Omega_{S}, \Omega_{v}\right) & r_{d h}\left(\Omega_{s}\right) \\ r_{h d}\left(\Omega_{v}\right) & r_{h h}\end{array}\right]$

where $r_{d d}\left(\Omega_{S}, \Omega_{v}\right)$ is the bi-directional reflectance, $r_{d h}\left(\Omega_{S}\right)$ is the directional-hemispherical reflectance (also called black-sky albedo), $r_{h d}\left(\Omega_{v}\right)$ is the hemispherical-directional reflectance (which is equal to $r_{d h}\left(\Omega_{v}\right)$ under the reciprocity law), and $r_{h h}$ is bi-hemispherical reflectance (also called white-sky albedo).

The determinant $|R|$ is easily calculated as

$\left|R\left(\Omega_{S}, \Omega_{v}\right)\right|=r_{d d}\left(\Omega_{S}, \Omega_{v}\right) r_{h h}-r_{d h}\left(\Omega_{S}\right) r_{d h}\left(\Omega_{v}\right)$,

It is evident that as long as the surface BRF is known, the surface reflectance matrix can be determined.

\subsection{BRF/albedo modeling}

BRF models quantify the angular distribution of radiance reflected by an illuminated surface. Various models have been proposed to 
simulate or capture the anisotropic characteristics of the land surface (Liang, 2007; Widlowski et al., 2007), including computer simulation models (Gastellu-Etchegorry et al., 2004), physical models using the canopy radiative transfer process (Kuusk, 1995a,b; Pinty et al., 2006), and (semi)empirical models based on various approximations of the radiative transfer process (Li \& Strahler, 1992; Rahman et al., 1993; Roujean et al., 1992). The quality of these models can be evaluated either through a comparison with simulations by other models of higher complexity, or through a comparison with measurements. In order to expedite the inversion procedure, complex computer simulation and physical models are not considered to be the optimal BRF model herein. Pokrovsky and Roujean (2003) made comparisons based on different kernel-based BRF models and found that the LiSparse and Roujean models perform best when fitting the bidirectional reflectances. Maignan et al. (2004) evaluated a set of analytical models based on POLDER measurements and proposed an improved Ross-Li kernel model by adding an angular factor based on Breon's finding (2002) to better account for the "hot spot" effect, which occurs when the viewing and illumination directions coincide. By introducing the multiple scattering between the canopy and the soil, and the relationship between the soil moisture and the soil reflectance into the Ross-Li kernel models, a recent method was proposed to build an angular and spectral kernel model (Liu et al., 2010). However, this method requires prior knowledge of soil moisture, which is difficult to obtain and therefore limits its operational application. Therefore, in this study, the improved Ross-Li kernel model proposed by Maignan et al. (2004) and Breon et al. (2002) is used to account for the surface anisotropic reflectance. It is given by

$R\left(\theta_{s}, \theta_{v}, \varphi\right)=f_{\text {iso }}+f_{\text {vol }} K_{v o l}\left(\theta_{s}, \theta_{v}, \varphi\right)+f_{\text {geo }} K_{\text {geo }}\left(\theta_{s}, \theta_{v}, \varphi\right)$,

where $\theta_{s}, \theta_{v}$, and $\varphi$ are the solar zenith, view zenith, and relative azimuth angles, respectively. $K_{v o l}\left(\theta_{s}, \theta_{v}, \varphi\right)$ and $K_{\text {geo }}\left(\theta_{s}, \theta_{v}, \varphi\right)$ are simplified kernels based on physical or empirical approximations over the specific illumination and viewing geometries. $K_{v o l}$ is based on the approximation of the radiative transfer within the canopy, whereas $K_{\text {geo }}$ is based on the distribution of the size and the orientation of surface canopies within a certain area. $f_{i s o}, f_{\text {vol }}$ and $f_{\text {geo }}$ are the coefficients for those kernels. Further details can be found in the referenced studies.

For the bias of the MODIS reflectance products, it has been reported (Wang et al., 2010) that the derived reflectance is underestimated at high solar or view zenith angles but is overestimated at low solar or view zenith angles. When the solar zenith angle increases beyond $70^{\circ}$, increases in the negative bias and the RMSE compared to the ground measurements have also been identified (Liu et al., 2009). The problem of the separation of atmospheric correction and surface BRF modeling could be one possible reason for this bias, which can be solved using the method proposed in this study. A recent study (Pinty et al., 2011) suggests that the possible underestimation of MODIS albedos may come from the insufficient angular sampling of the surface anisotropy. In order to resolve this second problem, one method is introduced here to correct the change in albedo caused by the illumination geometry and the diffuse skylight impacts, especially for a solar zenith angle larger than $70^{\circ}$. The method is based on the dependence of surface albedo on the solar zenith angle over snow-free land surfaces and uses the intensive observations of surface shortwave fluxes made by the U. S. Department of Energy Atmospheric Radiation Measurement (ARM) Program and SURFRAD Network (Yang et al., 2008).

\subsection{Integration of $B R F$ and spectral albedo}

An angular integration of BRF over all the viewing angles is required to calculate the albedo because only the directional reflectance can be calculated directly from the BRF models. Instead of directly calculating the integral, the same method proposed in the MODIS albedo estimating procedure (Strugnell \& Lucht, 2001) is used, based on the improved kernel models above, fitting the black-sky albedo with a polynomial function. In this study, a higher order of the polynomial function was used to achieve better accuracy

$$
\begin{gathered}
\alpha_{b s}\left(\theta_{s}\right)=f_{\text {iso }}\left(a_{0}+a_{1} \theta_{s}+a_{2} \theta_{s}^{2}+a_{3} \theta_{s}^{3}\right)+f_{\text {vol }}\left(b_{0}+b_{1} \theta_{s}+b_{2} \theta_{s}^{2}+b_{3} \theta_{s}^{3}\right) \\
+f_{\text {geo }}\left(c_{0}+c_{1} \theta_{s}+c_{2} \theta_{s}^{2}+c_{3} \theta_{s}^{3}\right)
\end{gathered}
$$

where $\theta_{s}$ is the solar zenith angle, and $a, b$, and $c$ are the regression coefficients. Similarly, the white-sky albedo can be computed by using the equation

$\alpha_{w s}=f_{i s o} a_{w}+f_{\text {vol }} b_{w}+f_{g e o} c_{w}$

The regression coefficients are listed in Table 1. Fig. 2 shows the fitting capability of the black-sky albedo using the polynomial function (Eq. 8). The calculated black-sky albedo from the regression coefficients matches the BRF-integrated albedo very well. Contrastingly, simply using the MODIS equations and coefficients will result in a 0.02 albedo difference in this case when the solar zenith angle is greater than $80^{\circ}$. Experiments on extending the polynomial function to a higher order show no significant improvement in the BRF/albedo fitting accuracy.

Most of the current land surface models and weather forecast applications use an albedo that can account for a wide range of wavelengths (e.g., total shortwave, total visible, and total near-infrared band). However, the BRF models are designed to carry out the calculation of all the components defined in the reflectance matrix (Eq. 5) individually for each spectral band. Moreover, the distribution of the downward solar radiation varies significantly with the change in aerosol density, precipitable water vapor content, ozone, and other profiles of atmospheric variables. As a result, the reflected solar radiation of the surface changes when the definition of the albedo changes. The spectral albedo needs to be converted into broadband albedo based on the spectral albedo characteristics over different surfaces and different atmospheric conditions. An approach for establishing the linear relationship between broadband albedo and the spectral value from each band has been proposed by Liang (2001). In the present study, the conversion equations are adopted from Liang (2001) and Stroeve et al. (2005), the latter providing an improved equation to derive the shortwave broadband albedo for snow-covered surfaces.

\subsection{Albedo climatology}

The climatology of the surface broadband albedo reflects both the seasonal and the inter-annual changes in the surface status. It is very important because it places constraints on the BRF retrieving procedure. The TOA radiance/reflectance observed by the satellite sensor can be biased by the calibration error or an inaccurate estimation of atmospheric components (e.g., ozone and water vapor). "Prior" information is much more reliable when its associated (co)variance is small whereas the calibrated TOA observations contain a large amount of noise. The "prior" can help the optimization procedure to achieve reasonable global optimal estimations. However, owing to persistent and transient cloud contamination as well as ephemeral and seasonal snow cover, most satellite albedo products contain a large number of gaps for a snow-free land surface. In this study, 10 years (2000-2009) of MODIS broadband albedo products and the corresponding quality control data (for detailed information please refer to the MODIS website) were collected. In the quality control data set, the broadband albedo values are identified as "good quality" and "other quality". To avoid the effects (e.g., cloud contamination and low BRF fitting accuracy), only "good-quality" data were used to 
Table 1

Coefficients used to calculate albedo from BRF parameters.

\begin{tabular}{|c|c|c|c|c|c|c|c|c|}
\hline Variable & $a_{0}$ & $a_{1}$ & $a_{2}$ & $a_{3}$ & $b_{0}$ & $b_{1}$ & $b_{2}$ & $b_{3}$ \\
\hline Value & 1.0 & 0 & 0 & 0 & -0.0374 & 0.5699 & -1.1252 & 0.8432 \\
\hline Variable & $c_{0}$ & $c_{1}$ & $c_{2}$ & $c_{3}$ & $a_{w}$ & $b_{w}$ & $c_{w}$ & \\
\hline Value & -1.2665 & -0.1662 & 0.1829 & -0.1489 & 1.0 & 0.2260 & -1.3763 & \\
\hline
\end{tabular}

calculate the 10-year mean of the broadband albedo over North America and Greenland. The standard deviation for multiyear broadband albedo data was calculated for the same time of year to reflect the inter-annual variation in albedo over the same location. Whitesky albedo products were used in this study with no solar zenith dependence (an example for Julian day 121 is shown in Fig. 3). Many gaps can be found over west and north Canada. When the latitude is greater than $50^{\circ}$, both the mean and the variation of the shortwave albedo values become very large. This indicates that the snow situation over these areas changes annually at this time of year, whereas over central North America and Greenland, the surface is quite stable. The multiyear mean of shortwave albedo is used as the climatology data in Eq. (1) and the one-year standard deviation is used as an approximation to the uncertainty of the climatology. In this study, a simple method was used to build the albedo climatology. Generating complete and continuous spatial-temporal albedo climatology is beyond the scope of this paper.

\section{Data}

\subsection{MODIS TOA reflectance and atmospheric products}

The sensor of MODIS has seven spectral bands within the shortwave range that can be used for land applications. The MODIS Level 1B (Collection 5) calibrated radiance data, together with their corresponding geo-location data, were collected and converted into the TOA bidirectional reflectances. According to Eq. (4), the total unknown variables to be estimated include three BRF kernel parameters for each spectral band and AOD for each observation time given that the aerosol type is known from MODIS product. For example, for $n$ clear observations cumulated within a sliding temporal window (the surface is assumed to be stable in the temporal window), the total number of unknown variables is $3 \times 7+n$. Here, to make the whole procedure invertible, the number of variables should be no more than the number of observations: $3 \times 7+n \leq n \times 7$. Therefore, $n$ should be at least four, which implies that four sets of MODIS clear sky TOA reflectances (one set $=$ seven bands) need to be collected within the temporal window to make it possible to retrieve the

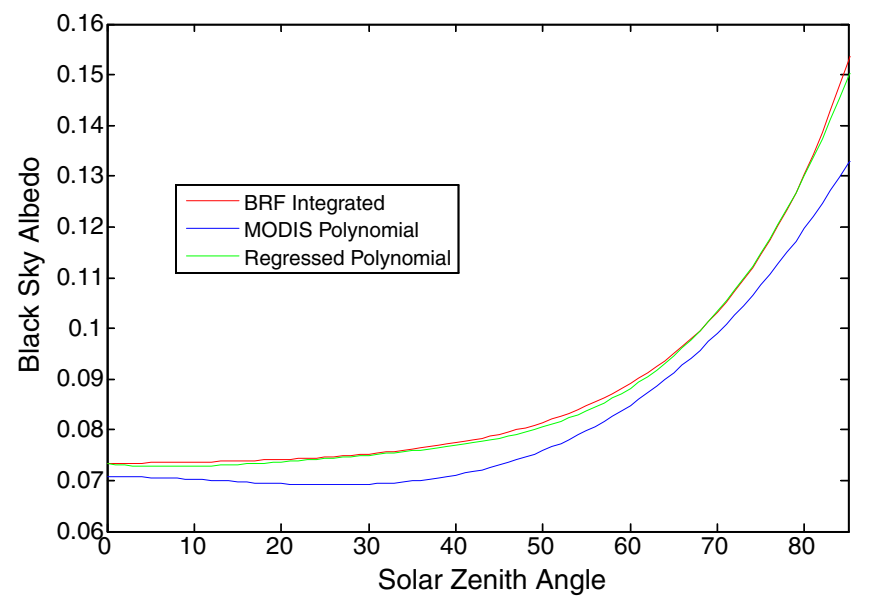

Fig. 2. Comparison of current polynomial and MODIS equation for angular integration based on Maignan's BRF kernel model. unknown variables. Since it is not always easy to obtain the angular sampling suitably within such a short temporal window, the BRF parameter retrievals from the preceding day were used as "first guess" constraints to limit the retrievals for the current procedure. MODIS level 2 cloud mask products (MOD35_L2/MYD35_L2) were used to screen cloudy observations. As a supplement to Terra MODIS, the one onboard Aqua (launched 2002) provides TOA observations as well. Commonly, over a mid-latitude location, there are two or three overpasses a day, combining data from Terra and Aqua. Considering that around two-thirds of the observations are under cloudy conditions over most of North America, the length of the temporal sliding window is usually less than seven days in order that a sufficient number of clear sky observations can be obtained for the retrieving procedure. During the winter season, the window size can be slightly smaller when the sky tends to be clearer than in other seasons. This is a great advantage for monitoring the rapid surface changes, especially for snow conditions.

\subsection{Atmospheric parameters}

To implement a forward simulation of TOA bidirectional reflectances using Eq. (4), parameters such as path reflectance, both upward and downward direct/diffuse transmittance and spherical albedo need to be calculated. In addition to simulating the TOA signal, the diffuse light ratio needs to be generated to produce the actual surface albedo considering the redistribution of solar illumination caused by aerosol scattering. Instead of an online calculation of these atmospheric functions on a point basis for every observation time, which will be computationally expensive, they were prepared as a function of the viewing geometries and AOD. The 6S software (Kotchenova et al., 2006) was used for the calculation of the LUT. It enables accurate simulations of satellite observation while accounting for elevated targets, the use of anisotropic and Lambertian surfaces, and the calculation of gaseous absorption based on the method of successive orders of scatterings approximations (Kotchenova et al., 2006). In this study, the following values were used as the entries in the $6 \mathrm{~S}$ simulations: solar zenith angle $\left(0^{\circ}-75^{\circ}\right.$, at $5^{\circ}$ intervals), viewing zenith angle $\left(0^{\circ}-75^{\circ}\right.$, at $5^{\circ}$ intervals), relative azimuth angle $\left(0^{\circ}-180^{\circ}\right.$, at $10^{\circ}$ intervals), AOD at $550 \mathrm{~nm}(0.01,0.05,0.1,0.15,0.2,0.3,0.4,0.6$, 0.8 , and 1.0) for five predefined aerosol types in $6 \mathrm{~S}$ software (urban, biomass, continental, desert, and maritime). Through the forward simulation, for each particular solar/viewing geometry and aerosol loading (AOD at $550 \mathrm{~nm}$ ), 6S generates path reflectance, upward and downward transmittances, spherical albedo, diffuse skylight ratio, and AOD for each of the seven MODIS bands respectively.

\subsection{Ground measurements}

The ground observational data used for this study were obtained from the SURFRAD website and the GC-Net web site. Details about instruments, data processing, and quality controls can be found on their websites.

For vegetated areas, the SURFRAD instruments measure surface downward and upward radiation. Based on the availability and quality of both satellite data and ground observations, this study used the SURFRAD observations at several sites (names and locations are listed in Table 2) for the year 2005. The SURFRAD sites provide the shortwave upward flux together with the downward global flux every 
a

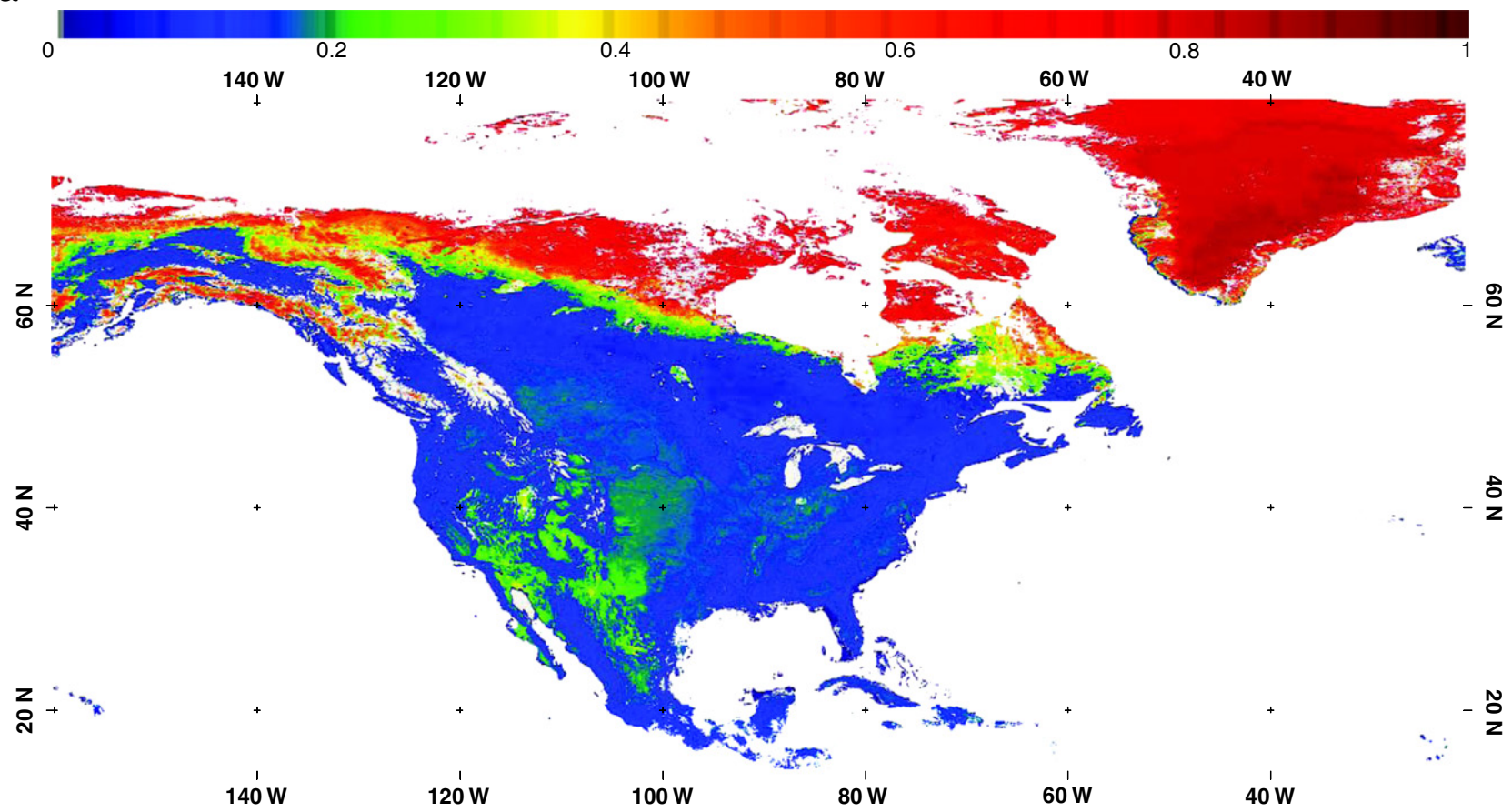

b

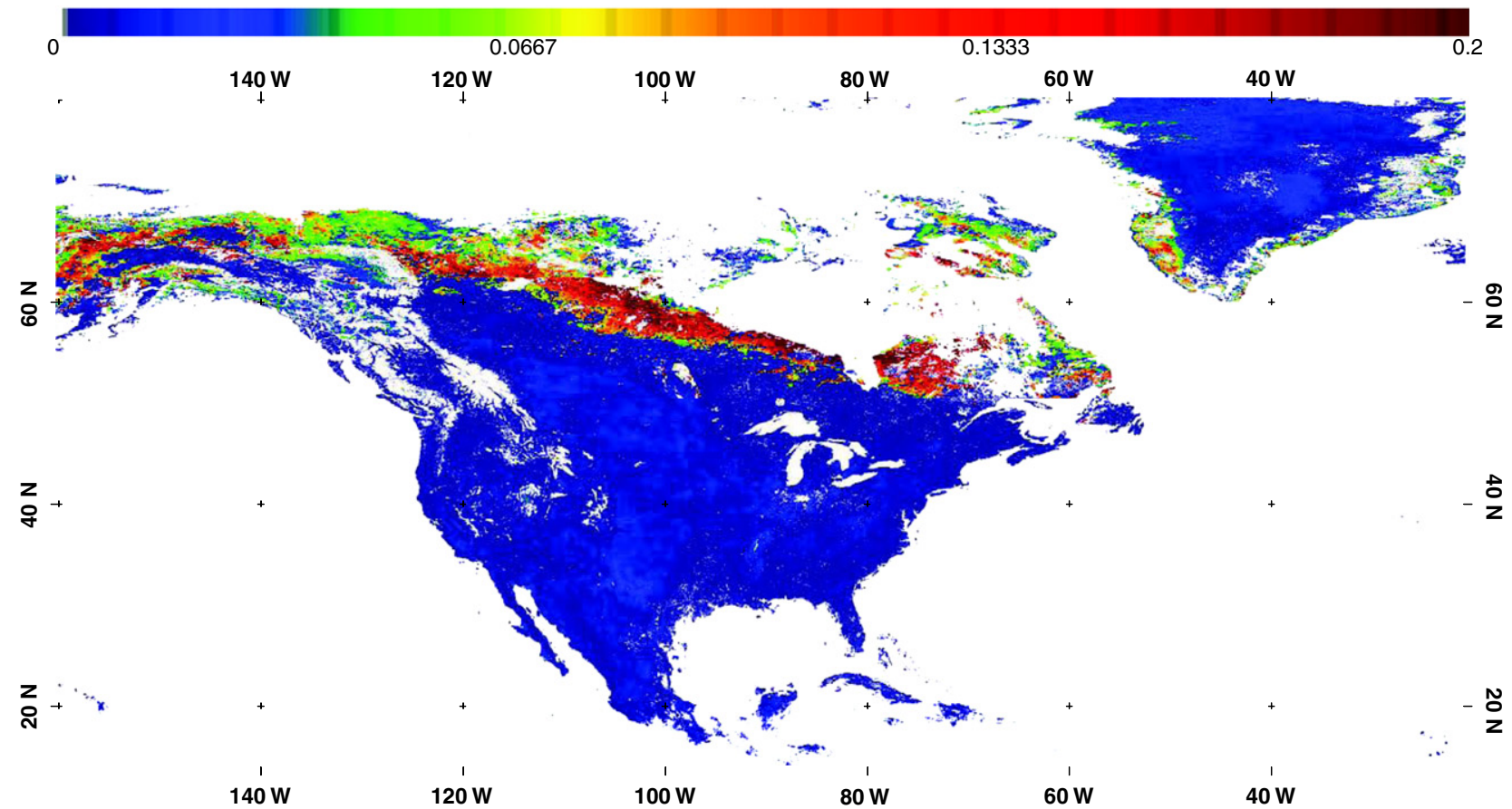

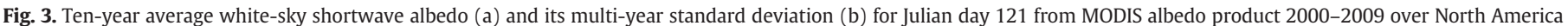
and Greenland (white color means water/ocean or lack of data).

three minutes. The "ground truth" blue-sky albedo was calculated by averaging the ratio between the upward and downward radiation within a 15-min range before and after the satellite observing time to reduce the ground measurement errors and temporal/partial cloud effects. In addition to radiation flux data, AOD measurements are also available at these sites. Aerosol information is measured for five channels $(415,500,614,670,868$, and $940 \mathrm{~nm})$ at a 2 -min temporal resolution. In order to make comparisons with AOD retrievals in this study, the ground measurements were converted to AOD at
$550 \mathrm{~nm}$ with the Angström exponent data provided and then averaged within \pm 10 -min range of the MODIS overpass time.

Ground radiation measurements over Greenland are regularly collected at GC-Net. This dataset provides unique and extensive observations, which can help verify the validity of this proposed algorithm over snow-covered surfaces. Shortwave upward and downward radiation at the surface is observed on an hourly basis. To account for the reduced sensitivity of the GC-Net instruments, ground data were preprocessed using the method proposed by Stroeve et al. (2005). The 
Table 2

SURFRAD site information.

\begin{tabular}{lll}
\hline Site name & Location & Land cover type \\
\hline Bondville, IL & $40.05 \mathrm{~N}, 88.37 \mathrm{~W}$ & Crop \\
Boulder, CO & $40.13 \mathrm{~N}, 105.24 \mathrm{~W}$ & Grass \\
Desert Rock, NV & $36.63 \mathrm{~N}, 116.02 \mathrm{~W}$ & Open shrub \\
Fort Peck, MT & $48.31 \mathrm{~N}, 105.10 \mathrm{~W}$ & Grass \\
Goodwin Creek, MS & $34.25 \mathrm{~N}, 89.87 \mathrm{~W}$ & Grass and forest \\
Penn State, PA & $40.72 \mathrm{~N}, 77.93 \mathrm{~W}$ & Crop \\
Sioux Falls, SD & $43.73 \mathrm{~N}, 96.62 \mathrm{~W}$ & Grass \\
\hline
\end{tabular}

"ground truth" blue-sky albedo was calculated based on that. Thirteen sites were chosen in this study according to data availability and data quality during the year 2003 (information listed in Table 3).

\subsection{MODASRVN data set}

Due to the limited spatial representation of ground measurements, it is always difficult to validate satellite pixel-based surface albedo estimations solely through comparison with ground measured data, especially when the pixel is not quite homogeneous. Using other satellite-derived data sources can help verify the algorithm estimations. Based on the ancillary information on aerosol and water vapor from the Aerosol Robotic Network (AERONET) sites, a set of surface albedo and reflectance data is retrieved through an independent atmospheric correction with the Ross-Li BRF kernel models using TOA data from MODIS observations (Wang et al., 2009). The MODASRVN data products from the year 2000 onwards are stored with the AERONET site in the center of the image covering $50 \times 50 \mathrm{~km}^{2}$ at $1-\mathrm{km}$ resolution.

According to the location, land cover type, and MODASRVN data availability from the AERONET sites, sixteen sites were chosen in this study for the validation of the estimated surface reflectance (see detailed information in Table 4). Similar to the ground measurement section, data for the year 2005 for MODASRVN and MODIS L1B TOA observations were collected and processed.

Cloud-screened AOD data from AERONET are available all year round at minimum intervals of 3-min for almost all the MODASRVN sites. Around 16 channels of AOD measurements are provided from $340 \mathrm{~nm}$ to $1640 \mathrm{~nm}$. Data were converted into AOD at $550 \mathrm{~nm}$ for comparison. Similar to the data processing for SURFRAD AOD, $\pm 10-$ min average AOD values were calculated.

\subsection{Algorithm implementation}

As mentioned in the previous section, MODIS TOA reflectances were calculated from the $1 \mathrm{~km}$ MODIS L1B dataset and collected within the sliding temporal window. Cloud pixels were excluded based on the MODIS cloud mask product. Following the flowchart in Fig. 1, all the clear sky observations were used in the retrieving procedure as long as they satisfied the minimum number required. The aerosol type was adopted from the MODIS aerosol product (MOD04/MYD04). Monthly statistics of AOD were calculated from the ground aerosol observations (Augustine et al., 2008; Holben et al., 2001) and used as a "first guess" in the retrieving process to constrain the AOD retrievals. BRF kernel parameters from the preceding day supported the radiative transfer and

Table 3

GC-Net site information.

\begin{tabular}{llll}
\hline Site name & Location & Site name & Location \\
\hline Swiss Camp & $69.57 \mathrm{~N}, 49.30 \mathrm{~W}$ & NASA-SE & $66.48 \mathrm{~N}, 42.50 \mathrm{~W}$ \\
JAR1 & $69.50 \mathrm{~N}, 49.68 \mathrm{~W}$ & NASA-E & $75.00 \mathrm{~N}, 30.00 \mathrm{~W}$ \\
JAR3 & $69.40 \mathrm{~N}, 50.31 \mathrm{~W}$ & GITS & $77.14 \mathrm{~N}, 61.10 \mathrm{~W}$ \\
Summit & $72.58 \mathrm{~N}, 38.50 \mathrm{~W}$ & DYE-2 & $66.48 \mathrm{~N}, 46.28 \mathrm{~W}$ \\
Saddle & $66.00 \mathrm{~N}, 44.50 \mathrm{~W}$ & & \\
\hline
\end{tabular}

Table 4

MODASRVN-AERONET site information.

\begin{tabular}{|c|c|c|c|c|c|}
\hline $\begin{array}{l}\text { Site } \\
\text { name }\end{array}$ & Location & Land cover & Site name & Location & $\begin{array}{l}\text { Land } \\
\text { cover }\end{array}$ \\
\hline Bondville & $\begin{array}{l}40.05 \mathrm{~N} \\
88.37 \mathrm{~W}\end{array}$ & Crop & Mexico City & $\begin{array}{l}19.33 \mathrm{~N} \\
99.18 \mathrm{~W}\end{array}$ & Urban \\
\hline GSFC & $\begin{array}{l}38.99 \mathrm{~N} \\
76.84 \mathrm{~W}\end{array}$ & $\begin{array}{l}\text { Forest and } \\
\text { urban }\end{array}$ & Rimrock & $\begin{array}{l}46.49 \mathrm{~N}, \\
116.99 \mathrm{~W}\end{array}$ & Grass \\
\hline Missoula & $\begin{array}{l}46.92 \mathrm{~N} \\
114.08 \mathrm{~W}\end{array}$ & $\begin{array}{l}\text { Grass and } \\
\text { urban }\end{array}$ & $\begin{array}{l}\text { MD Science } \\
\text { Center }\end{array}$ & $\begin{array}{l}39.28 \mathrm{~N} \\
76.62 \mathrm{~W}\end{array}$ & Urban \\
\hline SERC & $\begin{array}{l}38.88 \mathrm{~N} \\
76.50 \mathrm{~W}\end{array}$ & $\begin{array}{l}\text { Forest and } \\
\text { wetland }\end{array}$ & KONZAEDC & $\begin{array}{l}39.10 \mathrm{~N} \\
96.61 \mathrm{~W}\end{array}$ & Grass \\
\hline CARTEL & $\begin{array}{l}45.38 \mathrm{~N} \\
71.93 \mathrm{~W}\end{array}$ & $\begin{array}{l}\text { Grass and } \\
\text { urban }\end{array}$ & $\begin{array}{l}\text { BSRNBAO } \\
\text { Boulder }\end{array}$ & $\begin{array}{l}40.05 \mathrm{~N} \\
105.01 \mathrm{~W}\end{array}$ & Grass \\
\hline $\begin{array}{l}\text { Bratts } \\
\text { Lake }\end{array}$ & $\begin{array}{l}50.28 \mathrm{~N} \\
104.70 \mathrm{~W}\end{array}$ & Crop & $\begin{array}{l}\text { Railroad } \\
\text { Valley }\end{array}$ & $\begin{array}{l}38.50 \mathrm{~N}, \\
115.96 \mathrm{~W}\end{array}$ & Grass \\
\hline $\begin{array}{l}\text { Sioux } \\
\text { Falls }\end{array}$ & $\begin{array}{l}43.76 \mathrm{~N} \\
96.63 \mathrm{~W}\end{array}$ & Grass & Frenso & $\begin{array}{l}36.78 \mathrm{~N} \\
119.77 \mathrm{~W}\end{array}$ & Urban \\
\hline Egbert & $\begin{array}{l}44.23 \mathrm{~N} \\
79.75 \mathrm{~W}\end{array}$ & Crop & Halifax & $\begin{array}{l}44.64 \mathrm{~N} \\
63.59 \mathrm{~W}\end{array}$ & Urban \\
\hline
\end{tabular}

optimization process by providing the "first guess" BRF shape. This prior information can also help reduce the uncertainty that may be introduced by the insufficient angular sampling of the TOA signal during a short period of time. The SCE algorithm then searched for the optimal kernel parameters and instantaneous AODs, which best fit the satellite observations and the albedo climatology considering the error distributions for both parts of Eq. (1). The retrieved BRF models can generate bidirectional reflectances for all the seven spectral bands as well as spectral black-sky/white-sky albedos through angular integration based on Eqs. (8) and (9). With the retrieved AOD as an inference, the "blue-sky" albedo was calculated using Eq. (3) following the narrowband-to-broadband conversion based on spectral albedos.

\section{Results and discussions}

\subsection{SURFRAD sites}

Ground measurements from SURFRAD sites have been extensively used for validating the MODIS albedo product (Jin et al., 2003; Liu et al., 2009; Salomon et al., 2006). The direct comparisons of the retrieved albedo values with ground measurements and MODIS data over the seven SURFRAD sites are shown in the time series in Fig. 4, and the statistics listed in Table 5(a). MODIS 1-km albedo products (MCD43B3) and the corresponding quality products (MCD43B2) were used in this study. Only the best quality MODIS albedo values are shown for snow-free conditions in the comparison. While the MODIS albedo algorithm intends to produce snow-free albedo values, the total shortwave albedo products for snowy conditions are always flagged as having lower quality. Those snow data are included in the comparison, in black color.

Generally, the retrieved albedo values have a good match with the field measurements and MODIS albedos. The proposed algorithm in this study generates albedo estimates, which are very close to the MODIS data since large albedo changes are rarely encountered over the snow-free period especially for these vegetated sites. For the non-snow cases (Desert Rock and Goodwin Creek), the Root Mean Square Errors (RMSE) are quite small, although the $\mathrm{R}^{2}$ values are rather low due to the small range of albedo variations. At Goodwin Creek, both our estimations and the MODIS products are slightly lower than the field measurements.

Both our retrievals and the MODIS albedo data can represent the seasonal snow albedo over Bondville and Sioux Falls reasonably well. However, due to the failure of the MODIS albedo algorithm, the albedo values cannot reflect the snow covered situations in some cases, either due to a mismatch of the snow or a non-snow condition (e.g., around DOY 40 over Bondville) or to having filled values in winter (e.g., over Fort Peck). 

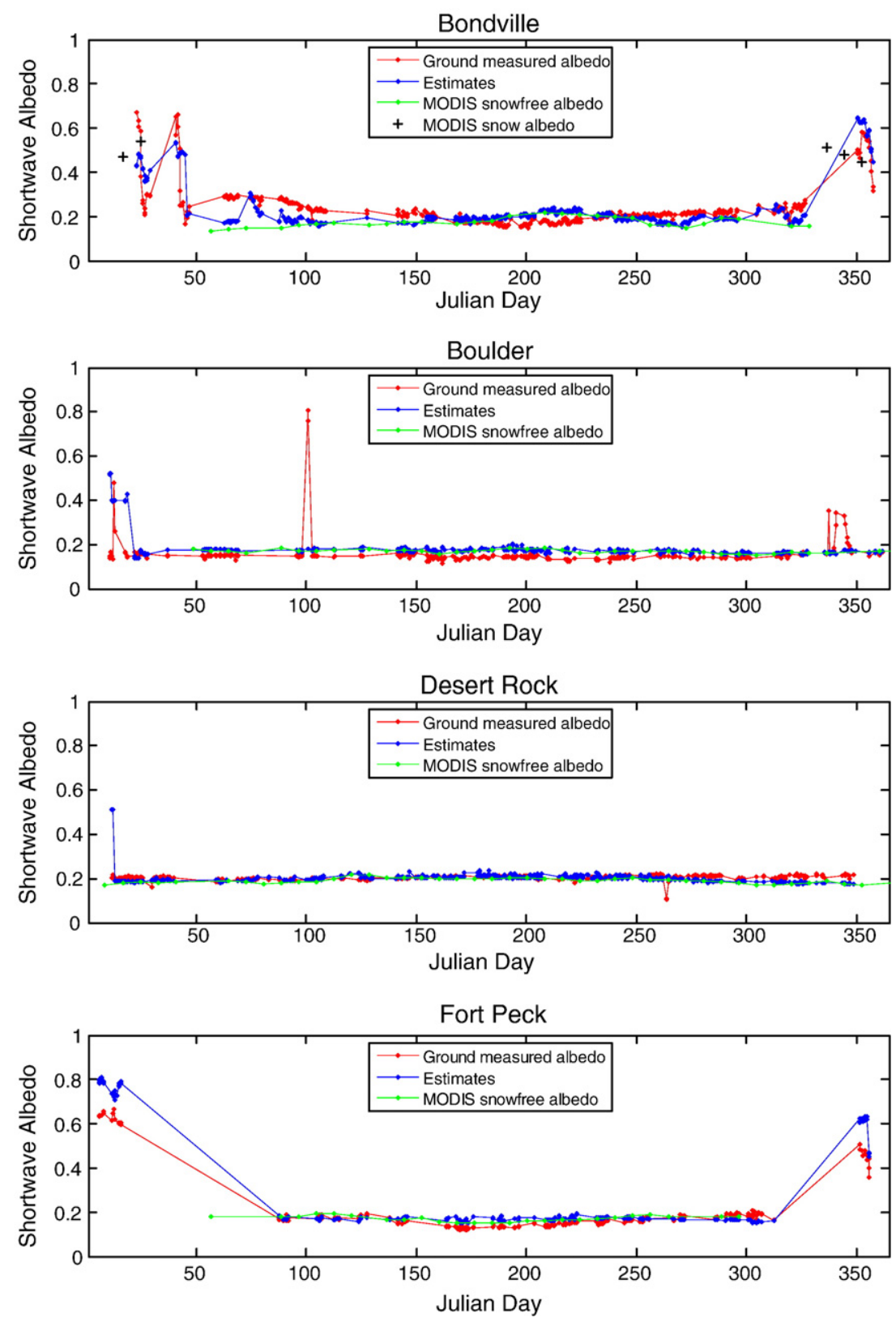

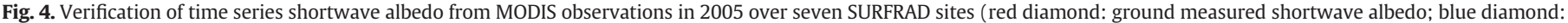
estimated albedo from MODIS observations; green diamond: MODIS 16-day snow-free albedo; black cross: MODIS 16-day snow albedo).

The proposed algorithm has difficulty deriving surface albedo over the site of Penn State in winter and early spring because of lack of available clear sky observations within the sliding window while the MODIS magnitude algorithm can produce some estimates.

Overall, the proposed algorithm in this study provides good estimations at all the seven sites with a small bias $(-0.0016)$ and RMSE (0.0268) for no snow conditions, and reasonable results for snow events (bias: 0.0324, RMSE: $0.1319, \mathrm{R}^{2}$ : 0.3855). Besides residual cloud contamination, the pixel mixture (e.g., partial snow and surface heterogeneity during the non-snow season) problem could be one of the main reasons for the bias found at Fort Peck and Goodwin Creek. It should be noted that the surface condition is very stable over some sites mainly covered by grass (e.g. Boulder, Desert Rock and Goodwin Creek). In these cases, the $\mathrm{R}^{2}$ can be quite low due to the small change in surface albedo and the reduced RMSE is observed as well.
Comparisons of AOD estimations from the proposed algorithm and the MODIS algorithm with ground measurements are provided along with the statistics in Table 5(b). MODIS instantaneous AOD data (Collection 5) from both Terra (MOD04_L2) and Aqua (MYD04_L2) observations were used in this comparison. For Bondville, significant positive bias and RMSE are found for both the retrieved AODs and MODIS estimations. The site's close vicinity to the urban area could be a main reason for the large aerosol variations, which may contribute to an underestimation of the albedo. The slight underestimation over Boulder is one of the possible reasons for the introduction of the positive bias in the albedo estimation. There are some overestimations over Desert Rock where the RMSE (0.0451) is the smallest among all the sites, indicating accurate surface albedo estimations and non-significant surface changes. However, the MODIS aerosol algorithm generates very few values over Desert Rock, which makes the comparison impossible. This is probably caused by 

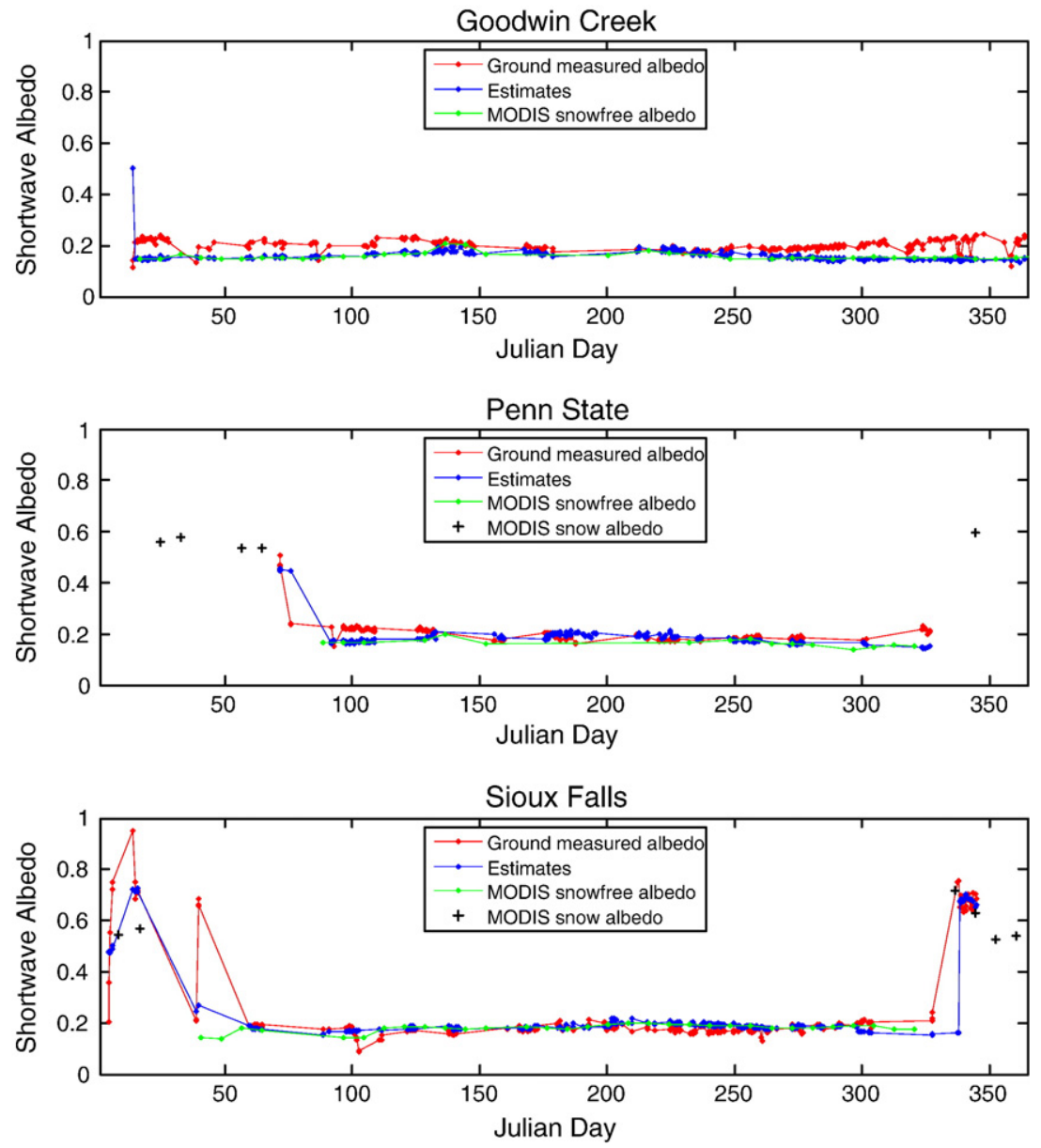

Fig. 4 (continued).

Table 5

Statistics of the retrieved values from this study with comparison to ground measurements over SURFRAD sites.

\begin{tabular}{|c|c|c|c|c|}
\hline \multicolumn{5}{|l|}{ (a) } \\
\hline Site name & \multicolumn{2}{|c|}{ Bias } & RMSE & $\mathrm{R}^{2}$ \\
\hline Bondville & \multicolumn{2}{|c|}{-0.0097} & 0.0615 & 0.6268 \\
\hline Boulder & \multicolumn{2}{|c|}{0.0245} & 0.0781 & 0.0086 \\
\hline Desert Rock & \multicolumn{2}{|c|}{-0.0033} & 0.0271 & 0.0013 \\
\hline Fort Peck & \multicolumn{2}{|c|}{0.0241} & 0.0541 & 0.9714 \\
\hline Goodwin Creek & \multicolumn{2}{|c|}{-0.0403} & 0.0581 & 0.1035 \\
\hline Penn State & \multicolumn{2}{|c|}{-0.0135} & 0.0390 & 0.4537 \\
\hline Sioux Falls & \multicolumn{2}{|c|}{-0.0031} & 0.0762 & 0.7884 \\
\hline All sites for no snow & \multicolumn{2}{|c|}{-0.0016} & 0.0268 & 0.0783 \\
\hline All sites for snow & \multicolumn{2}{|c|}{0.0324} & 0.1319 & 0.3855 \\
\hline \multicolumn{5}{|l|}{ (b) } \\
\hline \multirow[t]{2}{*}{ Site name } & \multicolumn{2}{|c|}{$\begin{array}{l}\text { Retrieved AOD vs } \\
\text { ground measurements }\end{array}$} & \multicolumn{2}{|c|}{$\begin{array}{l}\text { MODIS AOD vs ground } \\
\text { measurements }\end{array}$} \\
\hline & Bias & RMSE & Bias & RMSE \\
\hline Bondville & 0.0529 & 0.1283 & 0.0579 & 0.1416 \\
\hline Boulder & -0.0059 & 0.0567 & 0.0025 & 0.0612 \\
\hline Desert Rock & 0.0186 & 0.0451 & $\mathrm{n} / \mathrm{a}$ & $\mathrm{n} / \mathrm{a}$ \\
\hline Fort Peck & 0.0330 & 0.0654 & 0.0357 & 0.0986 \\
\hline Goodwin Creek & 0.0095 & 0.1271 & -0.0445 & 0.1290 \\
\hline Penn State & $\mathrm{n} / \mathrm{a}$ & $\mathrm{n} / \mathrm{a}$ & $\mathrm{n} / \mathrm{a}$ & $\mathrm{n} / \mathrm{a}$ \\
\hline Sioux Falls & 0.0232 & 0.0901 & -0.0480 & 0.1210 \\
\hline All sites & 0.0243 & 0.0984 & -0.0009 & 0.1187 \\
\hline
\end{tabular}

the increased surface reflectivity, which its algorithm is not capable of processing. Both Fort Peck and Goodwin Creek have large AOD variations; the uncertainty of aerosol retrievals may have deteriorated the albedo estimations. Due to the lack of ground measurements over Penn State, no comparison is made for this dataset. For Sioux Falls, the positive bias (0.0232) corresponds to the slight underestimation of albedo, while the impact is not very significant. Combining the comparisons for all the sites, the AOD values generated by the proposed algorithm have accuracy levels similar to those of the MODIS aerosol products. A positive bias $(0.0243)$ is found for the retrievals with a slightly smaller RMSE (0.0984) compared to that of the MODIS AOD (RMSE: 0.1187). The positive biases of the MODIS AOD data over Bondville (0.0579) and Fort Peck (0.0357) are offset by the negative ones over Goodwin Creek $(-0.0445)$ and Sioux Falls $(-0.0480)$ leading to a small bias $(-0.0009)$.

\subsection{GC-Net sites}

Similar to the comparisons made over the SUFRAD sites, the MODIS $1-\mathrm{km}$ albedo and quality data were processed for the GC-Net sites. Time series comparisons of ground measurements, retrieved albedo values, and MODIS albedo products over the GC-Net sites are given in Fig. 5. From the results shown here, snow and snow-melt events were clearly captured by the retrievals of our proposed algorithm. The results based on daily observations show variations in ground measurements and 

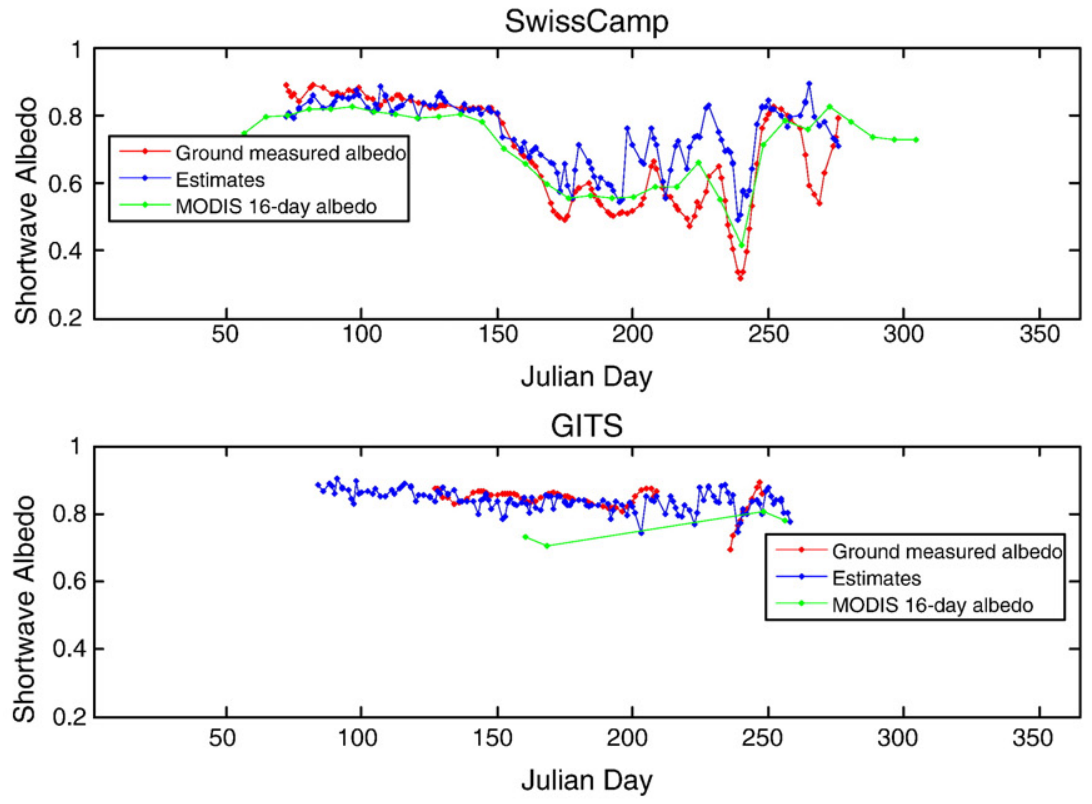

DYE-2

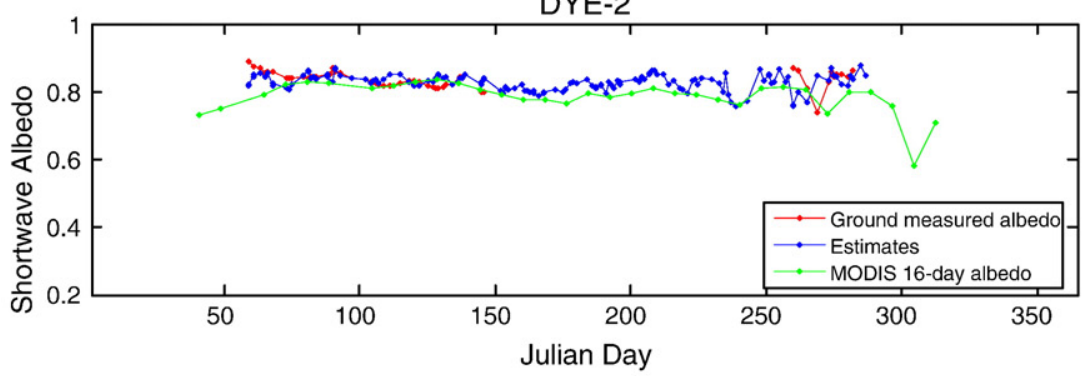

Saddle

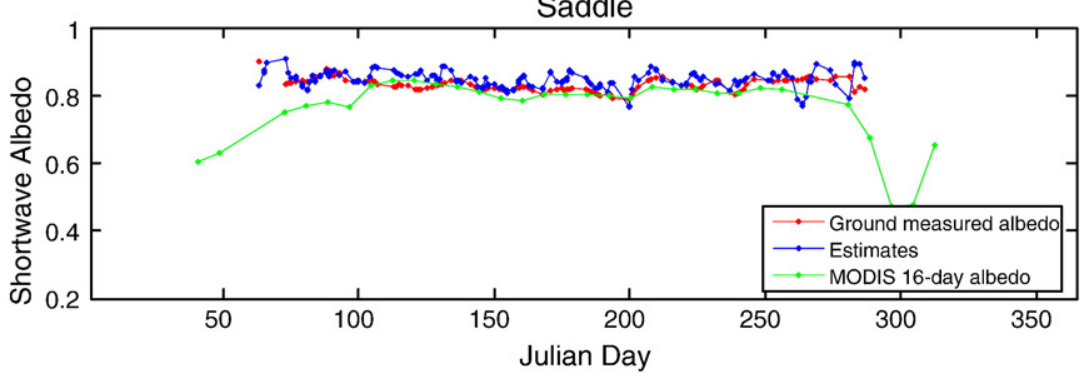

NASA-SE
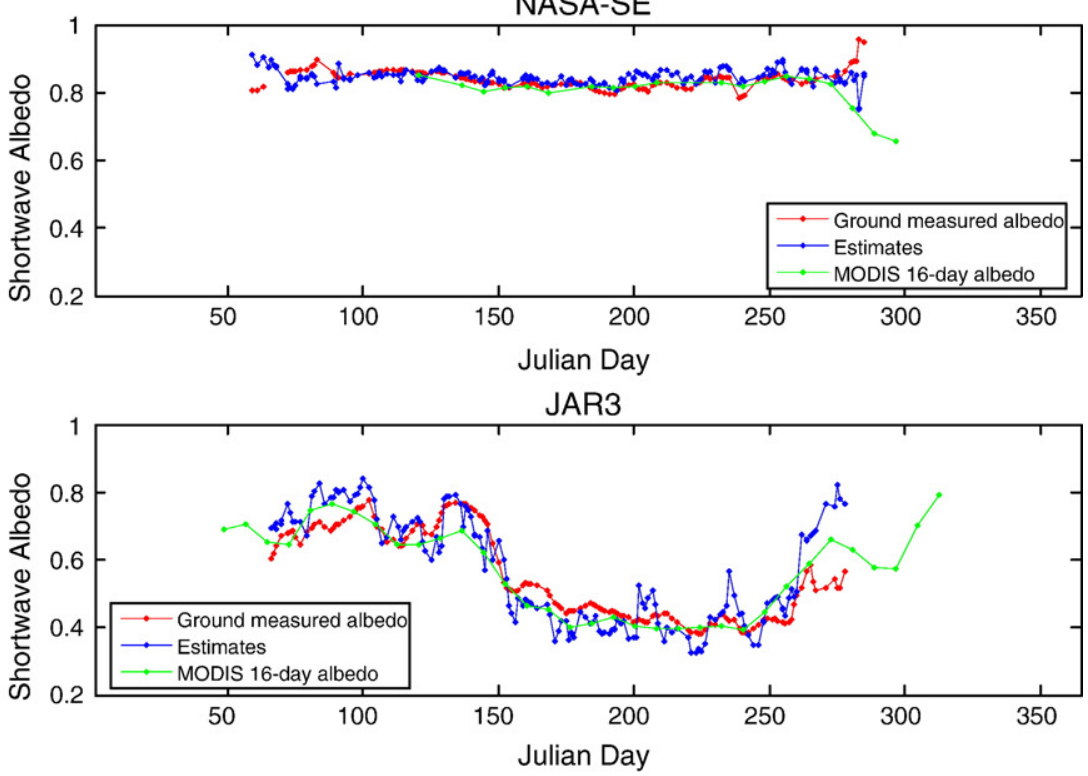
Table 6

Statistics of the retrieved values from this study with comparison to ground measurements over GC-Net sites.

\begin{tabular}{|c|c|c|c|}
\hline Site name & Bias & RMSE & $\mathrm{R}^{2}$ \\
\hline Swiss Camp & 0.062 & 0.1110 & 0.700 \\
\hline GITS & -0.011 & 0.0356 & 0.077 \\
\hline Summit & 0.0098 & 0.0467 & 0.027 \\
\hline DYE-2 & -0.0039 & 0.0333 & 0.006 \\
\hline JAR1 & 0.015 & 0.0910 & 0.872 \\
\hline Saddle & 0.015 & 0.0304 & 0.060 \\
\hline NASA-E & -0.024 & 0.0341 & 0.002 \\
\hline NASA-SE & 0.0074 & 0.0351 & 0.001 \\
\hline JAR3 & 0.0012 & 0.0767 & 0.774 \\
\hline All sites & 0.012 & 0.0654 & 0.842 \\
\hline
\end{tabular}

retrieved albedo data whereas the 16-day MODIS albedo curves are smooth over most cases. The albedo variations are caused by the changes in solar zenith angle, since MODIS can have multiple overpasses over Greenland in one day (combined Terra and Aqua). As more observations can be obtained over Greenland compared to those of the SURFRAD sites, the time range for collecting the cloud free observations becomes shorter over the Greenland sites, which gives the algorithm better capability for capturing rapid changes. The statistics of the comparisons between the instantaneous retrievals and ground measured albedo data over all the sites are given in Table 6. This algorithm gives a satisfactory result over all sites with a small positive bias (0.012). The overall $R^{2}(0.842)$ shows that the albedo retrievals have a good correlation with the ground measurements indicating that the snow surface changes can be well captured, although sometimes the sliding window size is still larger than the real situation given that the RMSEs are higher than 0.05 over some sites. Fig. 6 shows the comparison of the 16-day MODIS products and averaged retrievals and ground measurements over the same time period. The MODIS albedo data have a negative bias $(-0.027)$ while the retrieved values here have a much smaller bias of 0.013 . Furthermore, the retrieved albedos have a higher correlation with the ground measurements $\left(R^{2}: 0.838\right)$ and a smaller RMSE (0.0589) than those from MODIS $\left(R^{2}: 0.773\right.$, RMSE: 0.076). Unlike the seasonal albedo changes at the sites close to the seashore (e.g. Swiss Camp, JAR1, and JAR3), the snow albedo does not change significantly at the rest of the chosen sites due to fewer snow fall/melt events. The values of $R^{2}$ and RMSE are much lower for sites close to the center of Greenland due to the small albedo variation and possible misidentification of clouds over snow surface.

\subsection{Comparisons with MODASRVN data set}

Sixteen sites were chosen for validation of the surface reflectance using the MODASRVN data set. Time series comparisons of the red band and near-infrared band data over six vegetation sites are given in Fig. 7. The retrieved surface reflectances in these two bands capture the seasonal trends and match the MODASRVN instantaneous reflectance products very well. The difference plot in Fig. 7 shows that most of the errors lie in the range of \pm 0.05 for both bands and the errors are randomly distributed for a short time period. However, since in most cases the MODASRVN data failed to provide the reflectance over the snow covered surfaces, it is difficult to validate the proposed algorithm over bright surfaces using this dataset. Moreover, as this dataset relies only on the MODIS sensor onboard Terra, fewer retrievals are available than those in our results presented in this paper.

Direct comparisons are given in Fig. 8 (statistics listed in Table 7) over all sixteen sites for all 7 MODIS bands. The overall correlation of the retrievals and the MODASRVN data is very good for each individual band and the bias and RMSE are small. The $\mathrm{R}^{2}$ values are relatively small for band 3 and band 4 because there is only a narrow range for the reflectances $(0-0.2)$. Some outliers are found in the comparison, probably due to the misclassification of the cloud mask, which is
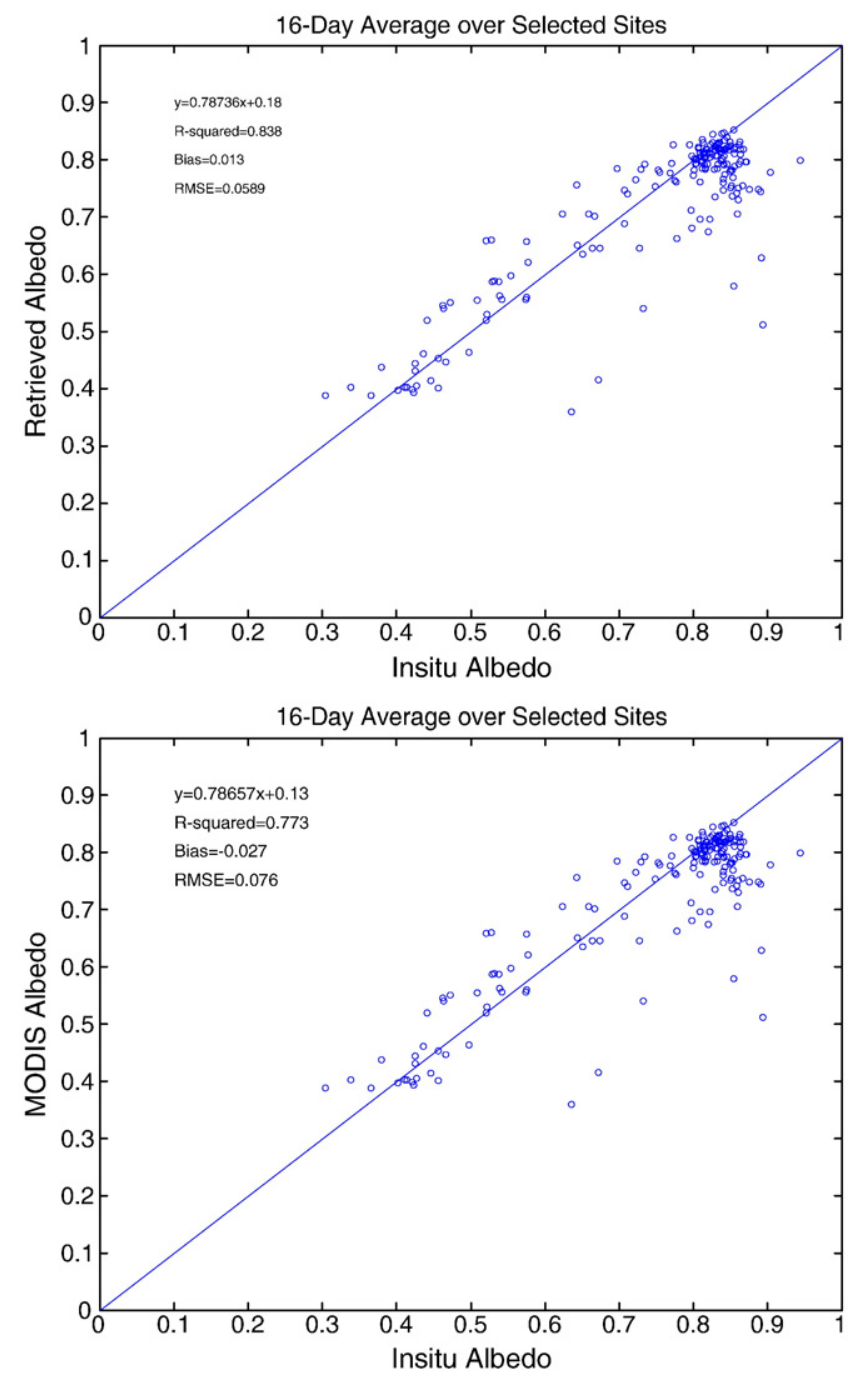

Fig. 6. Scattering plots of the retrieved albedo over nine GC-Net sites.

one of the major input components for this algorithm. Given the variability of surface cover types over all the sixteen sites, the results show that the algorithm proposed here is capable of handling different types of land cover regardless of its homogeneity.

The direct comparison of retrieved instantaneous AOD values with AERONET observations is shown in Fig. 9(a). The errors in the AOD estimates follow a normal distribution which shows a positive bias less than 0.03 . The overall results have a large RMSE (0.1017) which is larger than the MODIS AOD products shown in Fig. 9(b). Analysis has been carried out to investigate the performance of the algorithm in estimating AOD and therefore surface reflectance, and the statistics listed in Table 8. As MODIS passes over the same location only twice a day around local noon for mid-latitude sites (including Terra and Aqua), solar zenith is used here as the inference of the season - small values in summer and large values in winter. Solar zenith is divided into 6 segments: $15^{\circ}-25^{\circ}, 25^{\circ}-35^{\circ}, 35^{\circ}-45^{\circ}, 45^{\circ}-55^{\circ}, 55^{\circ}-65^{\circ}$, and $65^{\circ}-75^{\circ}$. The AOD estimation accuracies generally decrease with the increase of solar angles, which means better accuracies can be achieved during winter. There are two reasons for this. One is that summer has lower solar zenith but more variation of aerosol, while winter has large solar zenith with small aerosol accumulation. The other is that a large solar zenith angle provides a longer path from earth's surface to the satellite as well as more information on aerosol. The uncertainties of reflectance estimates 

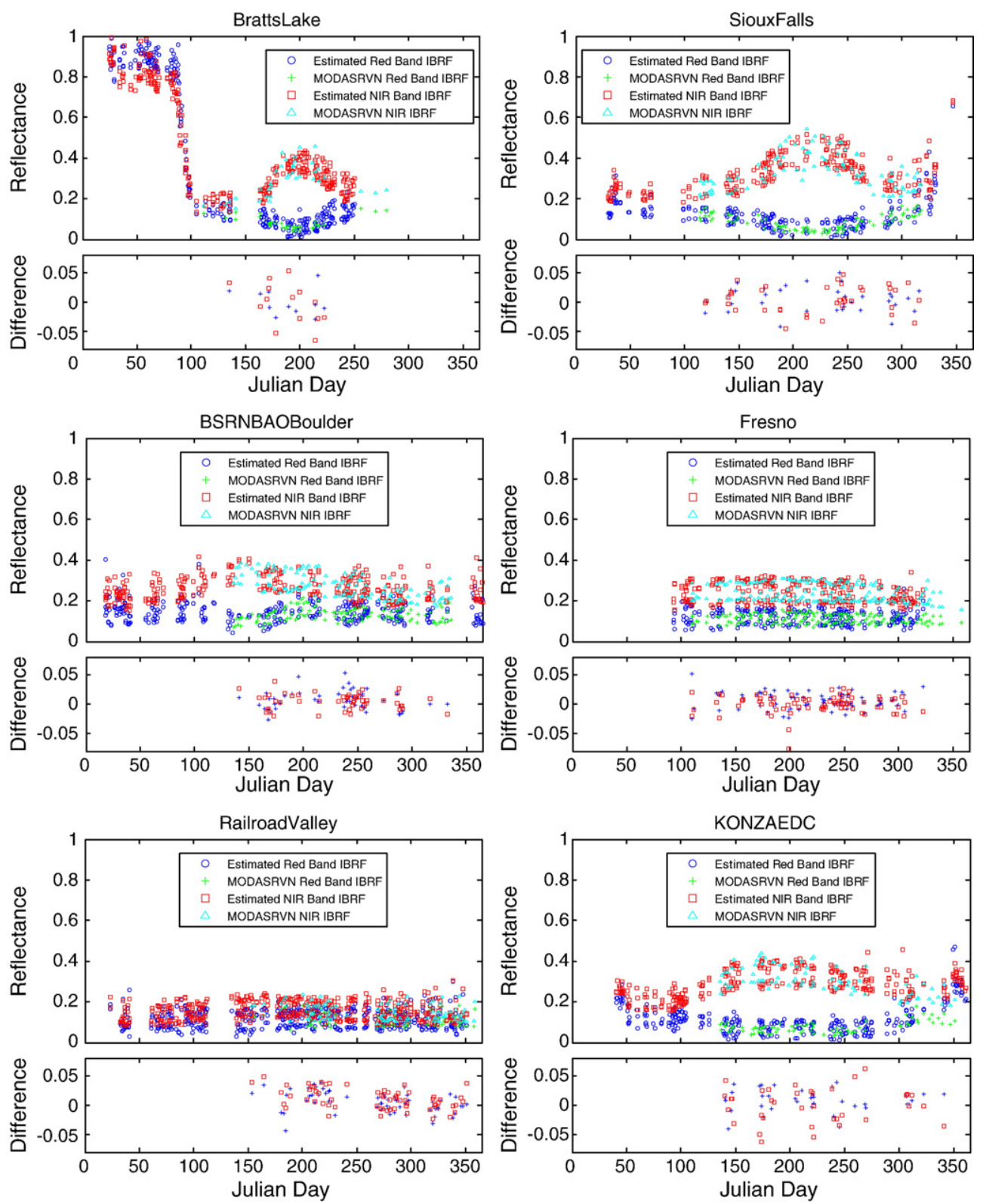

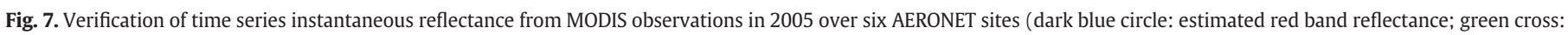

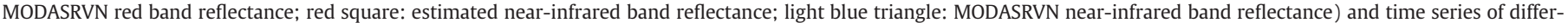
ences between the retrieved values and MODASRVN data (red square: difference for red band; blue cross: difference for near-infrared band).

also generally decrease with the increase of solar zenith when it is less than $55^{\circ}$. When the solar angle increases to $55^{\circ}-65^{\circ}$, there is a negative bias for each of the two bands. The underestimation may result from the difference of the two algorithms in accumulating the observations in the time period of partial snow.

Table 8 (b) shows the impacts of AOD estimation errors on the surface reflectance retrieving accuracies. Absolute AOD error values are divided into five ranges: $<0.05,0.05-0.10,0.10-0.15,0.15-0.20$, and $>0.20$. According to the statistics, the algorithm generates larger errors in reflectance for both bands when the AOD uncertainties become larger. As most of the AOD errors lie within the range of \pm 0.05 , the overall reflectance retrievals can have good accuracies in terms of the averaged errors.

\section{Summary and conclusions}

Based on the integration of the land-atmosphere radiation interaction framework, this study focuses on estimating the MODIS surface albedo and directional reflectance algorithm for possible use as a prototype of future Geostationary Operational Environmental Satellite RSeries (GOES-R) Advanced Baseline Imager (ABI) albedo estimation procedure because of its similar spectral bands. The major contributions of this study are as follows:

1) As existing algorithms deriving albedo products from geostationary satellite data mainly focus on the partitioning the contributions from atmosphere and surface, the "dark object" algorithm may bias the estimation of surface anisotropy. The proposed approach in this study is designed to mitigate this problem. This is the first prototype algorithm that estimates the surface albedo and reflectance for use with the future geostationary satellite GOES-R ABI sensor. This study provides the complete algorithm framework for the albedo retrieving procedure using MODIS observations as proxy data.

2) By using different "truth" datasets, this study provides extensive validation of the proposed algorithm by comparing the broadband 

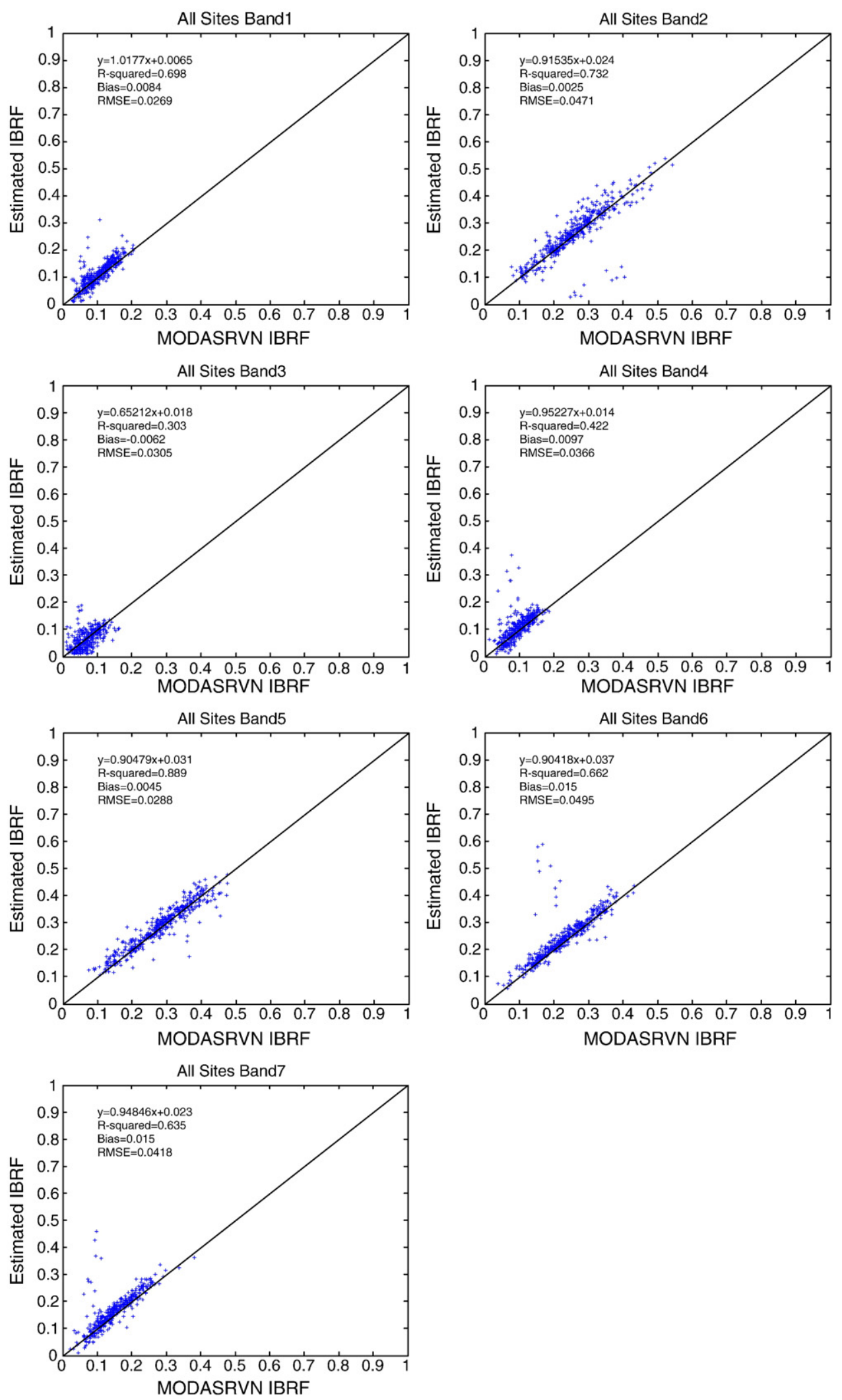

Fig. 8. Scatter plot of estimated and MODASRVN instantaneous bidirectional reflectance for each of the seven MODIS bands over all the selected AERONET sites during 2005.

albedos, spectral reflectances and instantaneous AODs. The overall results show that the retrievals are a good representation of the seasonal curves of the albedo and reflectance changes all year round. Compared with the MODIS albedo algorithm and MODIS AOD products, this proposed algorithm with a smaller sliding window provides reasonable results with relation to ground measurements for both surface albedo and AOD, while the capabilities in terms of handling rapid surface albedo changes caused by snowfall and snow-melt situations still need further investigations. This will help climate models in the simulation and forecast applications. 
Table 7

Statistics of the retrieved reflectance values from this study with comparison to MODASRVN reflectance products ground measurements over sixteen AERONET sites.

\begin{tabular}{lcll}
\hline Band no. & \multicolumn{1}{l}{ Bias } & RMSE & $\mathrm{R}^{2}$ \\
\hline 1 & 0.0084 & 0.0269 & 0.698 \\
2 & 0.0025 & 0.0471 & 0.732 \\
3 & -0.0062 & 0.0305 & 0.303 \\
4 & 0.0097 & 0.0366 & 0.422 \\
5 & 0.0045 & 0.0288 & 0.889 \\
6 & 0.015 & 0.0495 & 0.662 \\
7 & 0.015 & 0.0418 & 0.635 \\
\hline
\end{tabular}

Future work will focus on several major problems. First, efforts will be made on the mitigation of cloud effects and improvements over rapid change surfaces. Time series of previous retrievals/observations can be better used if clouds are persistent in the sliding window. Temporary cloud contamination or partial snow cover impacts can also be mitigated by introducing the previous retrievals as constraints in the current retrieving procedure. Since direct broadband albedo estimation can be carried out when limited clear skies are available, efforts will be made to incorporate and extend this algorithm to estimate both the broadband and spectral band albedos.

Second, the retrieved albedo values have some correlation with the climatology used in this study. While the observation data and climatology maps come from the same data source - MODIS, further efforts should be made to derive an unbiased climatology from multiple data sources. In addition, factors such as disturbance, precipitation and soil
Table 8

Impacts of solar zenith angle and estimation accuracies of AOD on surface reflectance estimations.

\begin{tabular}{|c|c|c|c|c|c|c|}
\hline \multicolumn{7}{|c|}{ (a) SZA on AOD and reflectance } \\
\hline SZA & $15^{\circ}-25^{\circ}$ & $25^{\circ}-35^{\circ}$ & $35^{\circ}-45^{\circ}$ & $45^{\circ}-55^{\circ}$ & $55^{\circ}-65^{\circ}$ & $65^{\circ}-75^{\circ}$ \\
\hline Mean $\left(\mathrm{E}_{\mathrm{AOD}}{ }^{*}\right)$ & 0.0311 & 0.0428 & 0.0333 & 0.0120 & 0.0079 & 0.0022 \\
\hline $\operatorname{STD}\left(\mathrm{E}_{\mathrm{AOD}}{ }^{*}\right)$ & 0.1204 & 0.1238 & 0.1015 & 0.0324 & 0.0251 & 0.0495 \\
\hline Mean $\left(E_{\mathrm{B} 1}{ }^{* *}\right)$ & 0.0121 & 0.0107 & 0.0186 & -0.0017 & -0.0139 & $\mathrm{n} / \mathrm{a}$ \\
\hline $\operatorname{STD}\left(\mathrm{E}_{\mathrm{B} 1}{ }^{* *}\right)$ & 0.0142 & 0.0190 & 0.0262 & 0.0128 & 0.0204 & $\mathrm{n} / \mathrm{a}$ \\
\hline Mean $\left(\mathrm{E}_{\mathrm{B} 2}{ }^{* * *}\right)$ & 0.0347 & 0.0292 & 0.0075 & 0.0016 & -0.0136 & $\mathrm{n} / \mathrm{a}$ \\
\hline $\operatorname{STD}\left(\mathrm{E}_{\mathrm{B} 2}{ }^{* * *}\right)$ & 0.0318 & 0.0442 & 0.0301 & 0.0226 & 0.0178 & $\mathrm{n} / \mathrm{a}$ \\
\hline \multicolumn{7}{|c|}{ (b) AOD on reflectance } \\
\hline Abs $\left(E_{A O D}{ }^{*}\right)$ & $<0.05$ & \multicolumn{2}{|c|}{$0.05-0.10$} & $0.10-0.15$ & $0.15-0.20$ & $>0.20$ \\
\hline Mean $\left(E_{\mathrm{R} 1}^{* *}\right)$ & 0.0035 & \multicolumn{2}{|l|}{0.0066} & 0.0204 & 0.0289 & 0.0184 \\
\hline $\operatorname{STD}\left(\mathrm{E}_{\mathrm{R} 1}{ }^{* *}\right)$ & 0.0189 & 0.0224 & \multicolumn{2}{|c|}{0.0204} & 0.0347 & 0.0246 \\
\hline Mean $\left(\mathrm{E}_{\mathrm{R} 1}{ }^{* * *}\right)$ & 0.0049 & 0.0278 & \multicolumn{2}{|c|}{0.0604} & 0.0278 & -0.0221 \\
\hline $\mathrm{STD}\left(\mathrm{E}_{\mathrm{R} 1}{ }^{* * *}\right)$ & 0.0254 & 0.0348 & \multicolumn{2}{|c|}{0.0534} & 0.0571 & 0.0394 \\
\hline
\end{tabular}

$\mathrm{E}_{\mathrm{AOD}}{ }^{*}$ : estimated AOD - AERONET AOD.

$\mathrm{E}_{\mathrm{B} 1}{ }^{* *}$ : estimated reflectance - MODASRVN reflectance for MODIS band 1.

$\mathrm{E}_{\mathrm{B} 2}{ }^{* * *}$ : estimated reflectance - MODASRVN reflectance for MODIS band 2.

moisture changes, will be taken into account in building the climatology. More efforts will be made on analyzing the covariance between different input data in Eq. (1).

Finally yet importantly, extensive validations need to be carried out using various sources of data that include finer-resolution satellite products. In addition, proxy data from a geostationary satellite (e.g., MSG/

a

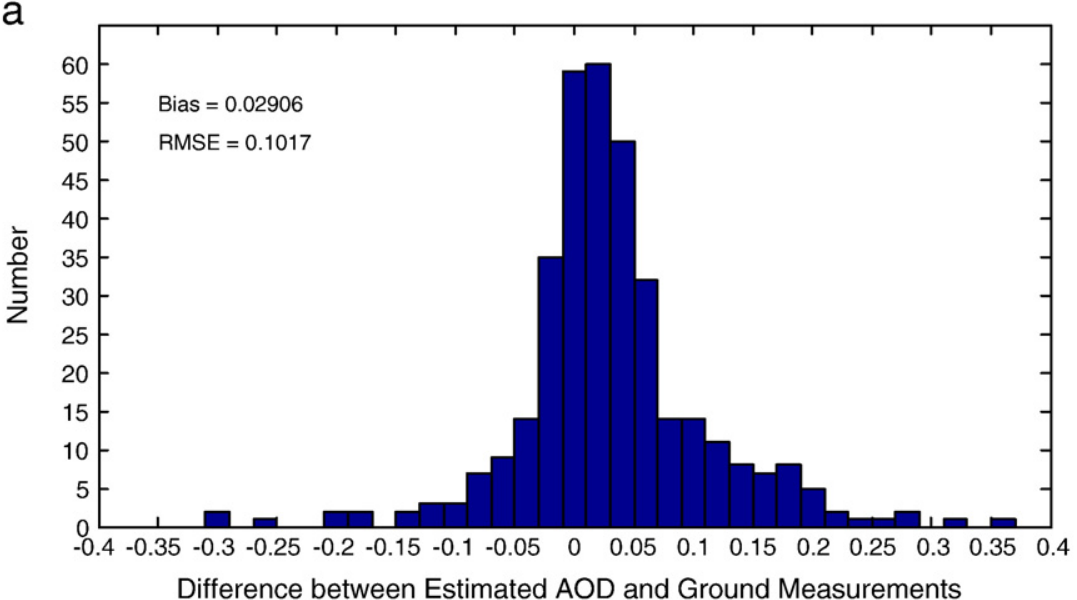

b

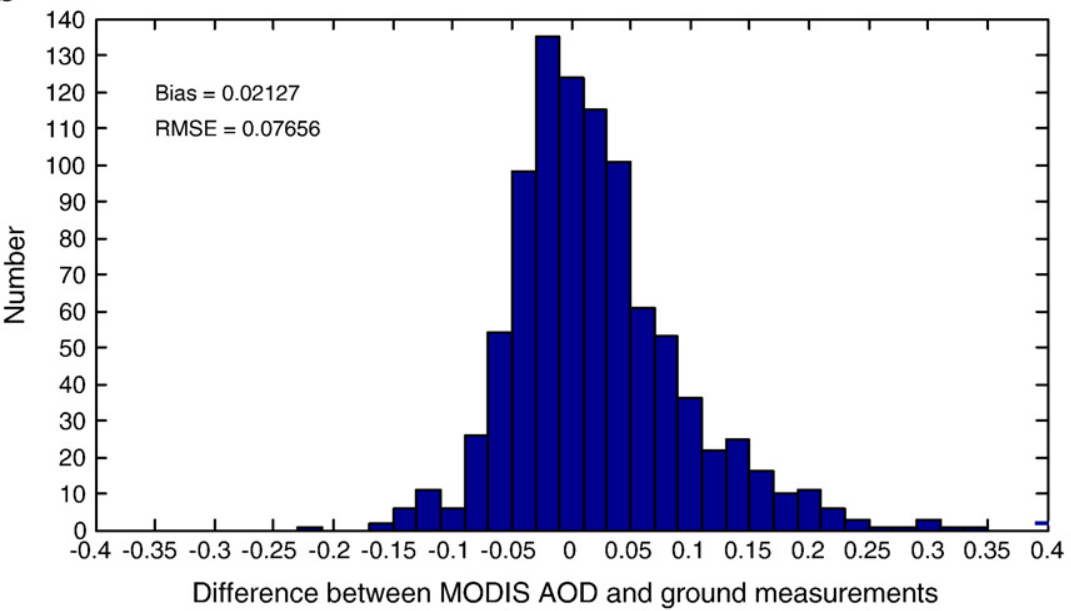

Fig. 9. AOD estimation accuracies from (a) the proposed algorithm and (b) the MODIS algorithm at MODASRVN sites during 2005. 
SEVIRI) will be used in evaluating this retrieving procedure for better understanding of the algorithm performance for future GOES-R ABI.

\section{Acknowledgments}

This research was supported by the Center for Satellite Applications and Research (STAR) of the National Oceanic and Atmospheric Administration (NOAA) under grant NA17EC1483. Many thanks to the reviewers of the manuscript. They provided valuable suggestions that helped improve our research work as well as the presentation of the contents in this paper. We gratefully acknowledge the MODIS team for providing access to the land and atmosphere products that are available online. We also thank the MODASRVN, SURFRAD, GC-Net, and AERONET teams for providing and maintaining all the data sets used for the validation of this study.

\section{References}

Augustine, J. A., Hodges, G. B., Dutton, E. G., Michalsky, J. J., \& Cornwall, C. R. (2008). An aerosol optical depth climatology for NOAA's national surface radiation budget network (SURFRAD). Journal of Geophysical Research-Atmospheres, 113.

Breon, F. M., Maignan, F., Leroy, M., \& Grant, I. (2002). Analysis of hot spot directional signatures measured from space. Journal of Geophysical Research-Atmospheres, 107, 15.

Dickinson, R. E. (1983). Land surface processes and climate surface albedos and energy balance. Advances in Geophysics, 25, 305-353.

Diner, D. J., Martonchik, J. V., Borel, C., Gerstl, S. A. W., Gordon, H. R., Myneni, R. B., et al. (1999). Level 2 surface retrieval algorithm theoretical basis document. NASA/JPL, JPL D-11401, Rev. D.

Duan, Q. Y., Gupta, V. K., \& Sorooshian, S. (1993). Shuffled complex evolution approach for effective and efficient global minimization. Journal of Optimization Theory and Applications, 76, 501-521.

Duan, Q. Y., Sorooshian, S., \& Gupta, V. K. (1994). Optimal use of the SCE-UA global optimization method for calibrating watershed models. Journal of Hydrology, 158, 265-284.

Gastellu-Etchegorry, J. P., Martin, E., \& Gascon, F. (2004). DART: A 3D model for simulating satellite images and studying surface radiation budget. International Journal of Remote Sensing, 25, 73-96.

Geiger, B., Carrer, D., Franchisteguy, L., Roujean, J. L., \& Meurey, C. (2008). Land surface albedo derived on a daily basis from Meteosat Second Generation observations. IEEE Transactions on Geoscience and Remote Sensing, 46, 3841-3856.

Govaerts, Y. M., Wagner, S., Lattanzio, A., \& Watts, P. (2010). Joint retrieval of surface reflectance and aerosol optical depth from MSG/SEVIRI observations with an optimal estimation approach: 1 Theory. Journal of Geophysical Research-Atmospheres, 115.

Holben, B. N., Tanre, D., Smirnov, A., Eck, T. F., Slutsker, I., Abuhassan, N., et al. (2001). An emerging ground-based aerosol climatology: Aerosol optical depth from AERONET. Journal of Geophysical Research-Atmospheres, 106, 12067-12097.

Jin, Y. F., Schaaf, C. B., Woodcock, C. E., Gao, F., Li, X. W., Strahler, A. H., et al. (2003). Consistency of MODIS surface bidirectional reflectance distribution function and albedo retrievals: 2. Validation. Journal of Geophysical Research-Atmospheres, 108.

Kotchenova, S. Y., Vermote, E. F., Matarrese, R., \& Klemm, F. J. (2006). Validation of a vector version of the $6 \mathrm{~S}$ radiative transfer code for atmospheric correction of satellite data. Part I: Path radiance. Applied Optics, 45, 6762-6774.

Kuusk, A. (1995). A fast, invertible canopy reflectance model. Remote Sensing of Environment, 51, 342-350.

Kuusk, A. (1995). A Markov-chain model of canopy reflectance. Agricultural and Forest Meteorology, 76, 221-236.

Leroy, M., Deuze, J. L., Breon, F. M., Hautecoeur, O., Herman, M., Buriez, J. C., et al. (1997). Retrieval of atmospheric properties and surface bidirectional reflectances over land from POLDER/ADEOS. Journal of Geophysical Research-Atmospheres, 102, 17023-17037.

Li, X. W., \& Strahler, A. H. (1992). Geometric-optical bidirectional reflectance modeling of the DISCRETE crown vegetation canopy effect of crown shape and mutual shadowing. IEEE Transactions on Geoscience and Remote Sensing, 30, 276-292.

Liang, S. L. (2001). Narrowband to broadband conversions of land surface albedo I Algorithms. Remote Sensing of Environment, 76, 213-238.

Liang, S. L. (2003). A direct algorithm for estimating land surface broadband albedos from MODIS imagery. IEEE Transactions on Geoscience and Remote Sensing, 41, 136-145.

Liang, S. L. (2007). Recent developments in estimating land surface biogeophysical variables from optical remote sensing. Progress in Physical Geography, 31, 501-516.

Liang, S. L., \& Strahler, A. H. (1994). 4-Stream solution for atmospheric radiative transfer over a non-Lambertian surface. Applied Optics, 33, 5745-5753.

Liang, S. L., \& Strahler, A. H. (1995). An analytic radiative transfer model for a coupled atmosphere and leaf canopy. Journal of Geophysical Research-Atmospheres, 100, 5085-5094.
Liang, S. L., Strahler, A. H., \& Walthall, C. (1999). Retrieval of land surface albedo from satellite observations: A simulation study. Journal of Applied Meteorology, 38, $712-725$.

Liang, S. L., Stroeve, J., \& Box, J. E. (2005). Mapping daily snow/ice shortwave broadband albedo from Moderate Resolution Imaging Spectroradiometer (MODIS): The improved direct retrieval algorithm and validation with Greenland in situ measurement. Journal of Geophysical Research-Atmospheres, 110.

Liu, S. H., Liu, Q. A., Liu, O. H., Wen, J. G., \& Li, X. W. (2010). The angular and spectral kernel model for BRDF and albedo retrieval. IEEE Journal of Selected Topics in Applied Earth Observations and Remote Sensing, 3, 241-256.

Liu, J. C., Schaaf, C., Strahler, A., Jiao, Z. T., Shuai, Y. M., Zhang, Q. L., et al. (2009). Validation of Moderate Resolution Imaging Spectroradiometer (MODIS) albedo retrieval algorithm: Dependence of albedo on solar zenith angle. Journal of Geophysical Research-Atmospheres, 114.

Maignan, F., Breon, F. M., \& Lacaze, R. (2004). Bidirectional reflectance of Earth targets: Evaluation of analytical models using a large set of spaceborne measurements with emphasis on the Hot Spot. Remote Sensing of Environment, 90, 210-220.

Meador, W. E., \& Weaver, W. R. (1980). 2-stream approximations to radiative transfer in planetary-atmospheres: A unified description of existing methods and a new improvement. Journal of the Atmospheric Sciences, 37, 630-643.

Nobre, C. A., Sellers, P. J., \& Shukla, J. (1991). Amazonian deforestation and regional climate change. Journal of Climate, 4, 957-988.

Pinty, B., Lavergne, T., Dickinson, R. E., Widlowski, J. L., Gobron, N., \& Verstraete, M. M (2006). Simplifying the interaction of land surfaces with radiation for relating remote sensing products to climate models. Journal of Geophysical ResearchAtmospheres, 111.

Pinty, B., Roveda, F., Verstraete, M. M., Gobron, N., Govaerts, Y., Martonchik, J. V., et al. (2000). Surface albedo retrieval from Meteosat - 1. Theory. Journal of Geophysical Research-Atmospheres, 105, 18099-18112.

Pinty, B., Taberner, M., Haemmerle, V. R., Paradise, S. R., Vermote, E., Verstraete, M. M. et al. (2011). Global-scale comparison of MISR and MODIS land surface albedos. Journal of Climate, 24, 732-749.

Pokrovsky, O., \& Roujean, J. L. (2003). Land surface albedo retrieval via kernel-based BRDF modeling: I. Statistical inversion method and model comparison. Remote Sensing of Environment, 84, 100-119.

Qin, W. H. Herman, J. R, \& Ahmad, Z (2001). A fast, accurate algorithm to account for non-Lambertian surface effects on TOA radiance. Journal of Geophysical ResearchAtmospheres, 106, 22671-22684.

Rahman, H., Pinty, B., \& Verstraete, M. M. (1993). Coupled Surface-Atmosphere Reflectance (CSAR) model .2. Semi-empirical surface model usable with NOAA Advanced Very High-Resolution Radiometer data. Journal of Geophysical ResearchAtmospheres, 98, 20791-20801.

Roujean, J. L., Leroy, M., \& Deschamps, P. Y. (1992). A bidirectional reflectance model of the Earth's surface for the correction of remote sensing data. Journal of Geophysical Research-Atmospheres, 97, 20455-20468.

Salomon, J. G., Schaaf, C. B., Strahler, A. H., Gao, F., \& Jin, Y. F. (2006). Validation of the MODIS bidirectional reflectance distribution function and albedo retrievals using combined observations from the Aqua and Terra platforms. IEEE Transactions on Geoscience and Remote Sensing, 44, 1555-1565.

Schaaf, C. B., Gao, F., Strahler, A. H., Lucht, W., Li, X. W., Tsang, T., et al. (2002). First operational BRDF, albedo nadir reflectance products from MODIS. Remote Sensing of Environment, 83, 135-148.

Sellers, P. J., Meeson, B. W., Hall, F. G., Asrar, G., Murphy, R. E., Schiffer, R. A., et al. (1995). Remote sensing of the land surface for studies of global change - Models, algorithms, experiments. Remote Sensing of Environment, 51, 3-26.

Stroeve, J., Box, J. E., Gao, F., Liang, S. L., Nolin, A., \& Schaaf, C. (2005). Accuracy assessment of the MODIS 16-day albedo product for snow: Comparisons with Greenland in situ measurements. Remote Sensing of Environment, 94, 46-60.

Strugnell, N. C., \& Lucht, W. (2001). An algorithm to infer continental-scale albedo from AVHRR data, land cover class, and field observations of typical BRDFs. Journal of Climate, 14, 1360-1376.

Wagner, S. C., Govaerts, Y. M., \& Lattanzio, A. (2010). Joint retrieval of surface reflectance and aerosol optical depth from MSG/SEVIRI observations with an optimal estimation approach: 2. Implementation and evaluation. Journal of Geophysical Research-Atmospheres, 115.

Wang, Y. J., Lyapustin, A. I., Privette, J. L., Cook, R. B., SanthanaVannan, S. K., Vermote, E. F., et al. (2010). Assessment of biases in MODIS surface reflectance due to Lambertian approximation. Remote Sensing of Environment, 114, 2791-2801.

Wang, Y. J., Lyapustin, A. I., Privette, J. L., Morisette, J. T., \& Holben, B. (2009). Atmospheric correction at AERONET locations: A new science and validation data set IEEE Transactions on Geoscience and Remote Sensing, 47, 2450-2466.

Widlowski, J. L., Taberner, M., Pinty, B., Bruniquel-Pinel, V., Disney, M., Fernandes, R. et al. (2007). Third Radiation Transfer Model Intercomparison (RAMI) exercise: Documenting progress in canopy reflectance models. Journal of Geophysical Research-Atmospheres, 112

Yang, F. L., Mitchell, K., Hou, Y. T., Dai, Y. J., Zeng, X. B., Wang, Z., et al. (2008). Dependence of land surface albedo on solar zenith angle: Observations and model parameterization. Journal of Applied Meteorology and Climatology, 47, 2963-2982.

Zhang, X. T., Liang, S. L., Wang, K. C., Li, L., \& Gui, S. (2010). Analysis of global land surface shortwave broadband albedo from multiple data sources. IEEE Journal of Selected Topics in Applied Earth Observations and Remote Sensing, 3, 296-305. 